Review Article

\title{
Nucleation and Growth During Recrystallization
}

\author{
Paulo Rangel Rios ${ }^{\mathrm{a}}$, Fulvio Siciliano Jr ${ }^{\mathrm{b}}$, Hugo Ricardo Zschommler Sandim ${ }^{\mathrm{c} *}$ \\ Ronald Lesley Plaut ${ }^{\mathrm{d}}$, Angelo Fernando Padilha ${ }^{\mathrm{d}}$ \\ ${ }^{\mathrm{a}}$ EEIMVR, UFF, 27255-125 Volta Redonda - RJ, Brazil \\ ${ }^{\mathrm{b}}$ CBMM, 04552-902 São Paulo - SP, Brazil \\ ${ }^{\mathrm{C}}$ DEMAR, FAENQUIL, 12600-970 Lorena - SP, Brazil \\ ${ }^{\mathrm{d}}$ Escola Politécnica, USP, 05508-900 São Paulo - SP, Brazil
}

Received: January 4, 2005; Revised: August 2, 2005

\begin{abstract}
The evolution in the understanding of the recrystallization phenomena is summarized in this paper. Initially the main developments concerning recrystallization are presented from a historical perspective. Definitions and concepts involving recrystallization are presented regarding it as a solid-state reaction that occurs by nucleation and growth. The recrystallization nucleation mechanisms are subsequently discussed. Finally, the growth step is highlighted, emphasizing boundary and sub-boundary mobilities and the forces acting on the high angle grain boundaries that sweep the microstructure during recrystallization.
\end{abstract}

Keywords: recrystallization, recrystallisation, recovery, nucleation, growth

\section{Historical Background}

The production of metallic materials is impressive not only due to the quantity produced, more than $10^{9}$ tons/year, but also due to its diversity. It is estimated that there are more than 40.000 metallic alloys. Forging, rolling, extrusion and drawing deform about $90 \%$ of the production of metals and alloys. The knowledge of the phenomena such as work hardening, recovery, recrystallization, and grain growth is of fundamental importance not only to correctly work these materials but also to control their microstructures and optimizing their properties.

The plastic working of metallic materials has been practiced for millennia. For instance, people that lived five thousand years ago in the regions next to the Persian Gulf, Irak nowadays, have mechanically worked copper, gold, and silver. Therefore, some knowledge concerning strain hardening, softening by annealing and by hot working was already available at that time. The knowledge available of these phenomena, at the time of the great discoveries, are well summarized in Biringuccio's quote in 1540 in the classical book De La Pirotechnia:

"Every work of gold and silver as well as copper may be worked either hot or cold, only you must be careful to anneal the thing at every hammering or when it needs it"

Kalisher $^{1}$, in 1881, in Germany, working with zinc strips, suggested that plastic deformation "destroyed the crystallinity" of the zinc, however subsequent annealing caused its restoration. It was then that the misleading term "recrystallization" has been given birth:

"Der Vorgang kann demnach so gedacht werden, dass das Zink seine krystallinische Struktur, die es beim Erstarren annimmt, durch das Walzen verliert und wenn es auf eine Temperatur erwaermt wird, welche diejenige, die es beim Walzen erhaelt, überschreitet, die krystallinische Struktur wiedergewinnt."

Usage of the optical microscope to observe steel microstructure, i.e. the invention of metallography by Sorby ${ }^{2,3}$, perhaps may have been the most important fact in the XIXth century, employed in studies of recrystallization. Later, Stead $^{4}$ affirms that recrystallization occurs by nucleation and growth, an important step forward to understand this solid state reaction. Ewing and Rosenhain $^{5-7}$, in works published in 1899 and 1900, mention that polygons (polyhedra, in three dimensions) that appear in the polished and etched surface of metallographic samples are crystals. Amongst other things, they conclude that metals deform plastically through slip of their crystal planes and that they do not loose crystallinity during deformation. However, only in 1911/12, von Laue ${ }^{8}$ discovered the diffraction of $\mathrm{X}$-rays on crystals, a powerful techhnique later used to confirm the cristallinity of metals. At the time of this experimental progress, crystallography was well established theoretically. For example, the book of Miller (A treatise on crystallography) edited in Cambridge in $1839^{\circ}$, has found fertile soil to develop and disseminate with aid of X-ray diffraction. In 1914, appeared the first book ${ }^{10}$ on this new area of knowledge, named physical metallurgy that later in the 60's would be transformed into materials science.

Recrystallization studies started and in 1920's the first reviews ${ }^{11,12}$ and the volume of results obtained and their importance were such that these phenomena were treated as a book chapter ${ }^{13}$. At the beginning of this decade, Alterthum ${ }^{14}$ published a work, which was conceptually very important, in which he affirms that recrystallization and grain growth have distinctive driving forces.

In 1924 , Wever ${ }^{15}$ published the first pole figures on cold rolled aluminum and iron. In 1931, Burgers and Louwerse ${ }^{16}$ have suggested that the recrystallization texture of aluminum single crystals was a result of oriented nucleation ("oriented nucleation theory"). The "oriented growth theory" only gained strength at the beginning of the 1950's, defended by Beck and collaborators ${ }^{17}$.

In 1934, Orowan ${ }^{18}$, Taylor ${ }^{19}$ and Polanyi ${ }^{20}$ presented, independently, the dislocation concept. The way was opened for the understanding of work hardening and the phenomena that occurred during annealing of a work hardened material, however, the experimental tools to get irrefutable microstructural evidences were still lacking.

Kinetic recrystallization studies were carried out nearly independently from the studies on recrystallization mechanisms. In 1940, it was already known that the recrystallization kinetics (recrystallized volume fraction as a function of time, for isothermal annealing conditions) followed the KJMA relationship (Kolmogorov ${ }^{21}$ - John- 
son-Mehl ${ }^{22}-$ Avrami $^{23-25}$ ). In 1941, the book of W. G. Burgers ${ }^{26}$ was published, probably the first book on recrystallization, a classical reference for many decades.

In 1949, R. W. Cahn ${ }^{27}$ published in the Journal of the Institute of Metals, as a Student Member, his classic work on polygonization during annealing of single crystals deformed plastically by bending. This work was an important milestone since it used in a pioneering manner the dislocation concepts and presented experimental evidence obtained by optical microscopy of the dislocation rearrangements during annealing of worked crystalline materials. Heidenreich ${ }^{28}$, also in 1949, observed for the first time, with the help of a transmission electron microscope (TEM), subgrains in aluminum. From that time the models of "recrystallization nucleation" by subgrain growth, proposed by Beck ${ }^{29}$ and $\mathrm{Cahn}^{30}$, and by strain induced migration of grain boundaries, proposed by Beck and Sperry ${ }^{31}$ were also introduced. Both models were suggested based upon observations made by optical microscopy.

Burke and Turnbull $^{32}$, in 1952, summarized the knowledge available at the beginning of the 1950's in a practical and objective way in the form of the so-called 7 "laws of recrystallization". It is interesting to observe that the fundamental concepts such as dislocation, nucleation and growth and crystallographic texture, have not been mentioned in the recrystallization laws.

With the advent of transmission electron microscopy and further improvements on the dislocation theory, the deformation substructure and its evolution during annealing could be investigated in greater detail. At the beginning of the 1960 's, Swann ${ }^{33}$ studied the dislocation arrangement of metals and alloys with a FCC structure. Keh e Weissmann ${ }^{34}$ did the same for the BCC metals and alloys. In particular, important papers like those written by $\mathrm{Hu}^{35,36}$, proposing recrystallization nucleation via subgrain coalescence by subgrain rotation and those from Bailey and Hirsch ${ }^{37}$, observing in detail the migration of strain induced grain boundaries during annealing, must be listed. In both cases, transmission electron microscopy was essential to observe substructures and crystalline defects.

At the end of the 1950's, Lücke and Detert ${ }^{38}$ proposed the first quantitative theory on the interaction of solutes and moving grain boundaries. At the beginning of the 1960's, Doherty and Martin ${ }^{39}$ showed that precipitate dispersions can either accelerate (coarse dispersion; large dispersed precipitates) or retard (fine dispersion; small close precipitates) the recrystallization.

In the early 1970's, a group of researchers of Sussex University, having R. W. Cahn and R. D. Doherty as leaders, started the series of experimental studies ${ }^{40-44}$ about the influence of deformation heterogeneities on recrystallization and subsequent modeling ${ }^{45}$. Still in the 1970's, Haeßner organized in Stuttgart a series of presentations on different aspects of recrystallization, given by a dozen of invited specialists. These presentations have been edited in a book form in 1971, whose second edition published in $1978^{46}$ much contributed to the organizing of the knowledge and nomenclature of the area.

During the 80 's, two improvements in experimental techniques have been made available, more powerful for the study of recrystallization and related phenomena. One of them was the improvement of the techniques related to determine local orientation relationships (in the $\mu \mathrm{m}$ range) in crystalline materials, particularly the diffraction of backscattered electrons ("Electron Backscattered Diffraction - EBSD), utilizing the Kikuchi lines generated in the scanning electron microscope ${ }^{47}$. With the help of EBSD it became possible to determine, with relative accuracy and speed, the orientation of a large number of micro-regions with dimensions of the order of about $0.3 \mu \mathrm{m}$ or less, with the aid of field emission gun scanning electron microscopes (FEG-SEM). This technique allows obtaining the orientation distribution (macrotexture and microtexture) and the boundary character distribution (mesotexture) in both deformed and recrystallized materials, as well as the detailed study of the type of grain boundaries ${ }^{48,49}$. Another notable improvement occurred in the technique of determining the velocity (mobility) of boundaries and interfaces in solids ${ }^{50}$. For example, nowadays grain boundary migration velocity in aluminum at high temperatures can be assessed in a continuous manner with accuracy in the range of 0.5 to $2 \%$.

Finally, it should be mentioned that the great advance that occurred in the last years in the area of recrystallization seems to be due, once again, to the improvements in experimental techniques: the development of 3-D metallography with the use of high energy $\mathrm{X}$-rays from synchrotron radiation beams for real-time in situ investigations $^{51}$.

\section{Definitions and Characteristics of Recrystallization}

The microstructural changes occurring during annealing of a cold-worked metal lead to the decrease of the stored energy due to plastic deformation. This energy decrease is caused by mechanisms of rearrangement and annihilation of crystal defects. According to Hae $\beta n r^{52}$, the main changes are: 1) reaction of point defects leading to their decrease; 2) dislocation annihilation of opposite signs and shrinking of dislocation loops: 3 ) dislocation rearrangement in order to form lower energy configurations (e.g., low angle grain boundaries); 4) formation of high angle grain boundaries; 5) absorption of point defects and dislocations by migrating high angle grain boundaries; and 6) reduction in total grain boundary area. The microstructural modifications 1), 2), 3) and 4) are classified as recovery and the modifications 5) and 6) are classified as recrystallization and grain growth, respectively (Haeßner mentions only 5 processes). As the crystalline defects distribution after straining is in general heterogeneous, each material region can go through a sequence of microstructural changes as mentioned, at different times.

The "continuous" or "in situ recrystallization" terms have probably been used for the first time by Hornbogen ${ }^{53}$ at the end of the 60 's for the case of aluminum alloys containing a dispersion of fine precipitates, in which recrystallization was inhibited but which softened considerably due to recovery ("extended recovery"). Until then, "continuous recrystallization" and "extended recovery" were considered synonymous. More recently, Humphreys and Chan ${ }^{54}$ proposed to differentiate "extended recovery" from "continuous recrystallization" as a function of the relative quantity between high and low angle grain boundaries that were present in the microstructure. To that extent, the definition suggested by Haeßner and adopted in this text is in agreement with the proposal of Doherty ${ }^{55}$ :

"I would describe recrystallization as the change in grain structure of material by application of thermal annealing to samples that had been plastically deformed so as to eliminate almost all the dislocations introduced by the deformation by means of migration of high angle grain boundaries. This definition by including plastic deformation, removal of dislocations and migration of high angle grain boundaries covers almost all the major features of this process of changing the grain structure."

Despite of the fact that recrystallization may be understood and treated as an irreversible, thermally activated solid state reaction which occurs by nucleation and growth, it presents numerous specific aspects that are worth mentioning:

a) The driving force for recrystallization (stored energy due to deformation in the form of crystalline defects) is very small when compared to other solid-state reactions (see item 4) and is practically independent of recrystallization temperature.

b) The classical theory of nucleation does not work well for recrystallization, because apart from the low driving force, 
the interface energy between the recrystallized region and the non-recrystallized matrix (high angle grain boundary) is very high. As a consequence we have large nuclei, in the order of $\sim 1 \mu \mathrm{m}$ or $\sim 10^{10}$ atoms, and it is difficult to imagine them as due to fluctuations.

c) Recrystallization nucleation means formation and migration of large angle grain boundaries stemming from pre-existing embryos.

d) There is experimental evidence of at least three nucleation mechanisms.

e) The start ("nucleation") occurs in an extremely heterogeneous manner, predominantly at deformation heterogeneities.

f) When compared to other solid state reactions, a small number of nuclei per unit volume are formed. From each million of "embryos" (deformation cells or subgrains) only one of them transforms into a nucleus.

g) After the initial nucleation stage only growth occurs, i.e., recrystallization is mostly a site-saturation solid state reaction.

h) In general, growth velocity decreases with time. The reasons for this decrease in growth velocity with time are deformation gradients in the microstructure resulting from the deformation and competition with concurrent recovery.

i) The resulting recrystallized grain size is very sensitive to the applied strain and less sensitive to the annealing temperature.

\section{Nucleation or Start of Recrystallization}

As we mentioned before, the term nucleation will be adopted in this text to indicate the beginning of recrystallization. The mechanisms of dislocation rearrangements in order to form a low dislocation density region associated with a large angle grain boundary with high mobility and therefore, capable of a fast migration over the strained (or recovered) matrix, will be defined as recrystallization nucleation.

It is unlikely that the classical homogeneous nucleation theory can be fully applied to recrystallization due to its low driving force unlike those ones associated with solidification or solid-state precipitation. Furthermore, grain boundary energies are much higher than those observed in other solid state reactions. In this regard, thermal fluctuations themselves cannot explain the formation of defect-free regions bounded by high angle grain boundaries upon annealing. Hence, the "nuclei" which give rise to the new recrystallized grains are not formed during annealing; they are already present in the de- formed state. The deformation structures with high local orientation gradients constitute the pre-deformed nuclei. In this type of analysis, transition and shear bands are potential sites where these pre-nuclei may trigger recrystallization. The three best-known recrystallization nucleation models are described in the following.

\subsection{Migration of pre-existing high angle boundaries}

This model has been originally suggested by Beck e Sperry ${ }^{31}$ based upon observations made by optical microscopy and later studies with transmission electron microscopy by Bailey ${ }^{37,56,57}$ in $\mathrm{Cu}, \mathrm{Ni}, \mathrm{Au}$, $\mathrm{Ag}$ and $\mathrm{Al}$. In these studies, the metals were deformed less than $40 \%$. This mechanism takes into account the migration of a pre-existing grain boundary toward the interior of a more highly strained grain, as shown in Figure 1.

The condition for the process to occur is the favorable energybalance between the decrease of stored energy due to the elimination of defects caused by the passage of the boundary and the increase in total grain boundary surface due to bulging. Figure 2 illustrates the model schematically. The growth condition is given by:

$$
L>\frac{2 \cdot \gamma}{\Delta E}
$$

where $\gamma$ is the grain boundary surface energy per unit area and $\Delta \mathrm{E}$ is the released energy associated with the decrease in defects.

\subsection{Nucleation by low angle boundary migration (sub-boundaries)}

This model has been suggested independently by Beck $^{29}$ and $\mathrm{Cahn}^{30}$ and with further improvements made by Cottrell ${ }^{59}$ and is generally quoted in the literature as being the Cahn-Cottrell model. The model is based upon the polygonization phenomena where regions of low dislocation densities are surrounded by sub-boundaries. Once a subgrain is formed, it will be capable of growing at the expense of its neighbors by thermally assisted subgrain boundary migration. In this way, a decrease in stored energy will occur during annealing due the removal and rearrangement of microstructural defects. The moving sub-boundary absorbs dislocations, increasing its orientation difference, its energy and mobility until it is transformed into a high angle boundary, hence characterizing nucleation. Sandström and collaborators ${ }^{60}$ observed the subgrain growth in pure aluminum at temperatures of 300 to $400{ }^{\circ} \mathrm{C}\left(0.6\right.$ and $0.7 \mathrm{~T}_{\mathrm{m}}$, respectively, were $\mathrm{T}_{\mathrm{m}}$ is the absolute melting point), showing that this was the operative mechanism at higher temperatures. Varma and Willits ${ }^{61}$ observed

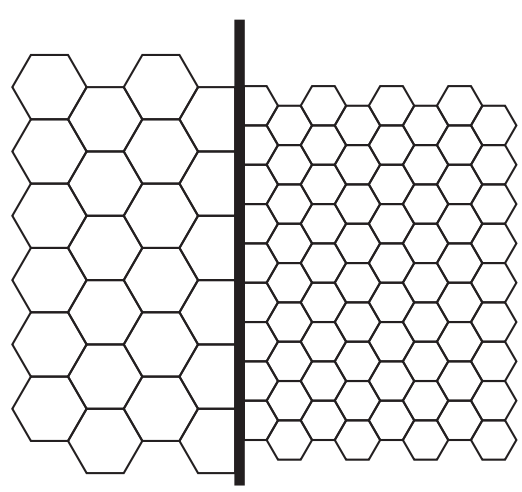

Grain A
Grain B

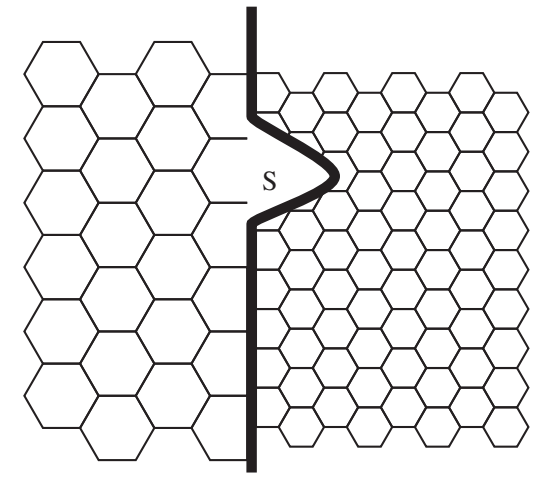

Grain A
Grain B

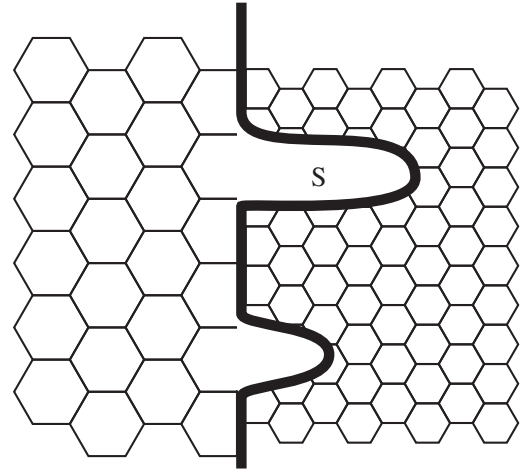

Grain A
Grain B

Figure 1. Schematic representation of nucleation by migration of boundaries induced by deformation ${ }^{58}$. 
essentially the same. Walter and Koch ${ }^{62}$ observed the mechanism of nucleation by migration of sub-boundaries associated with transition bands in a $\mathrm{Fe}-3 \% \mathrm{Si}$ alloy using transmission electron microscopy. More recent experimental evidence on the migration of low angle boundaries during hot deformation was observed in pure aluminum and in $\mathrm{Al}-5 \% \mathrm{Mg}$ alloy ${ }^{63}$. Figure 3 illustrates schematically the mechanism of recrystallization start by sub-boundary migration.

\subsection{Nucleation by subgrains coalescence}

This model has been postulated in 1948 by C. S. Smith ${ }^{64}$ and further studied on $\mathrm{Fe}-3 \% \mathrm{Si}$ single crystals by $\mathrm{Hu}^{35,36}$. $\mathrm{Li}^{65}$ analyzed the process from the point of view of kinetics and thermodynamics

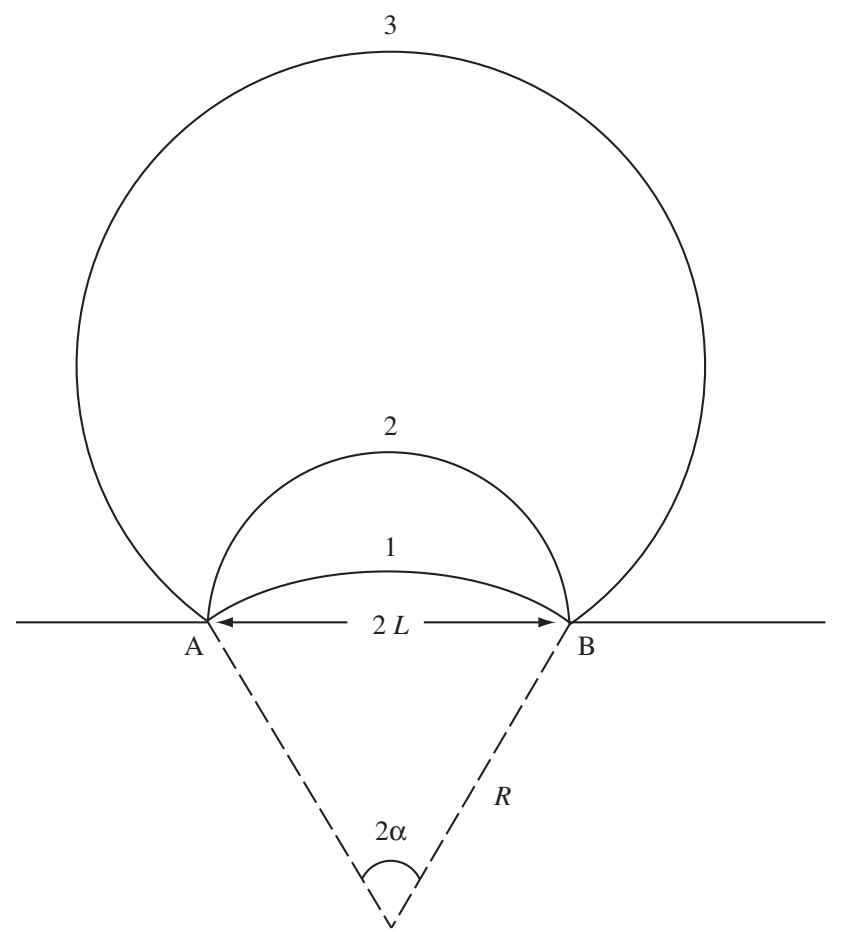

Figure 2. Model for the grain boundary migration induced by deformation, showing the successive migration stages 1,2 and $3^{57}$. and concluded that it was a sluggish process. Later, Doherty and Szpunar ${ }^{66}$ showed that coalescence of subgrains at temperatures lower than $0.65 \mathrm{~T}_{\mathrm{m}}$ would be a kinetically viable process. Transmission electron microscopy observations carried out by Jones ${ }^{67-69}$ have shown the occurrence of the coalescence of two neighboring subgrains in aluminum. The mechanism was based upon the coalescence of two adjacent subgrains and which is equivalent to a rotation, causing the crystal lattices to coincide, as shown in Figure 4.

Still quoting the systematic study of Sandströn and co-authors ${ }^{60}$, subgrain coalescence has been observed in aluminum using transmission electron microscopy, for temperatures of 0.4 and $0.5 \mathrm{~T}_{\mathrm{m}}$. Therefore, experimental evidences suggest that subgrain coalescence, when compared to subgrain migration, is favored for lower annealing temperatures.

Coalescence is a mechanism that promotes subgrain growth, disappearance of sub-boundaries (decreasing the stored energy) and changing the orientation differences between a group that went through coalescence and its neighboring subgrains. The increase in the orientation difference leads to the appearance of a high angle boundary capable of high-speed migration, forming the nucleus of recrystallization. It is important to point out that the global energy balance that takes into account the disappearance of sub-boundaries with the increase in orientation difference and the energy of others, is favorable, i.e., leads to a decrease in total free energy. Figure 5 illustrates schematically the formation of a nucleus by subgrain coalescence.

\section{The Role of Deformation Heterogeneities on Nucleation}

Plastic deformation rarely occurs in a homogeneous manner in most cases. In particular, single crystals of special orientations and coarse-grained specimens tend to display very heterogeneous deformation structures. In many cases, this heterogeneity is caused by the macroscopic subdivision of grains. Deformation heterogeneities like deformation and transition bands subdivide individual grains into distinct regions. Within each region, plastic deformation occurs in a quite homogeneous manner but different from the neighboring regions.

Deformation heterogeneities are regions that contain a larger quantity of crystalline defects per unit volume and present also larger

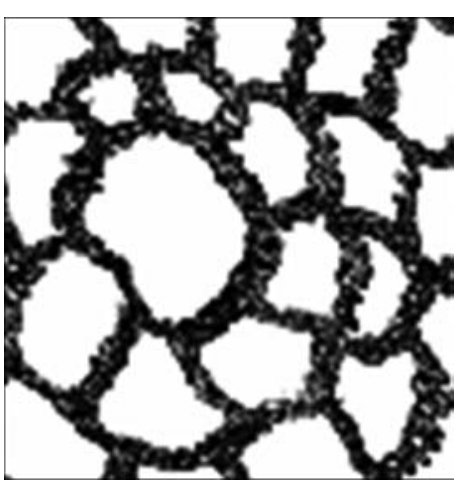

(a)

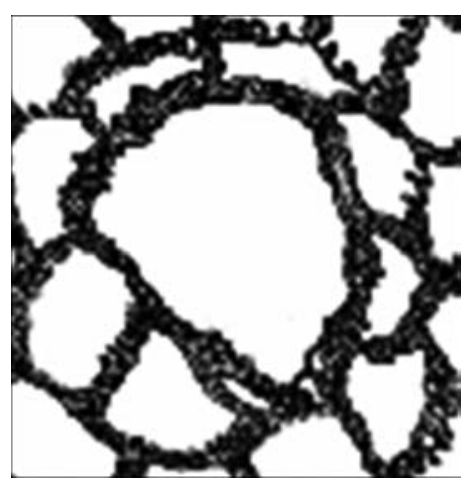

(b)

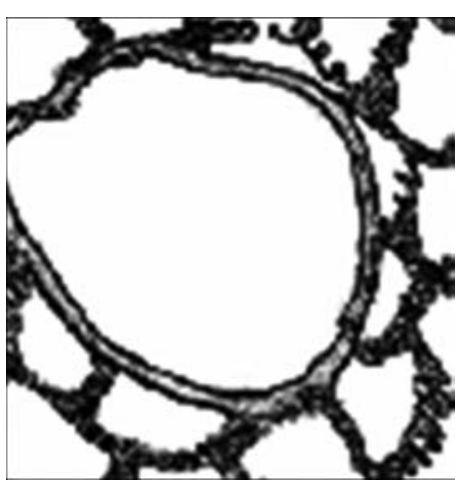

(c)

Figure 3. The sequence shows the nucleation of a recrystallized grain starting from a subgrain: a) initial substructure; b) the larger (middle) subgrain growth over the other (smaller) ones; and c) an area free of defects associated to a large angle boundary that is being formed. 


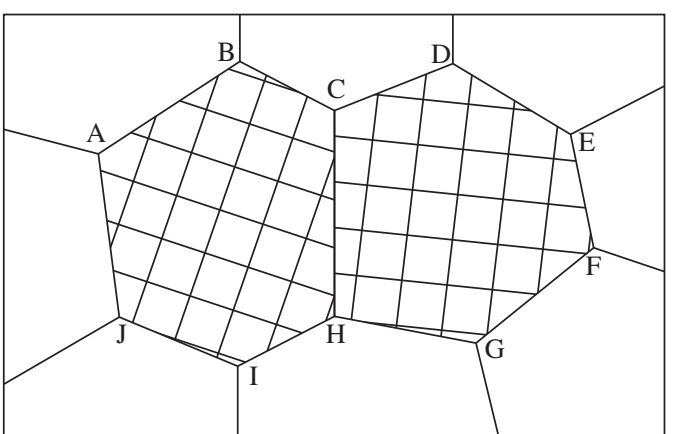

(a)

The original subgrain structure before coalescence

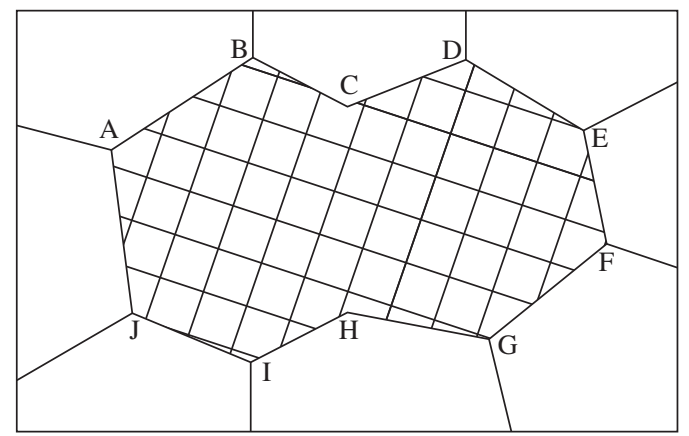

(c)

The subgrain structure just after coalescence

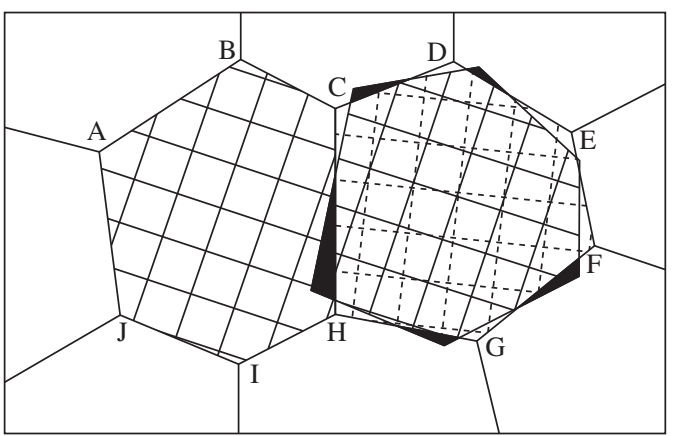

(b)

One subgrain is undergoing a rotation

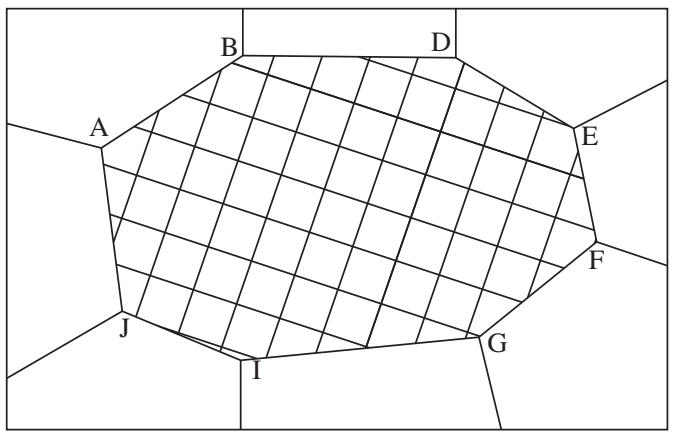

(d)

The final subgrain structure after some subboundary migration

Figure 4. Coalescence of two subgrains by "rotation" of one of them: a) original structure prior to coalescence; b) rotation of the CDEFGH grain; c) subgrain structure subsequent to coalescence; and d) final structure after sub-boundaries migration ${ }^{65}$.

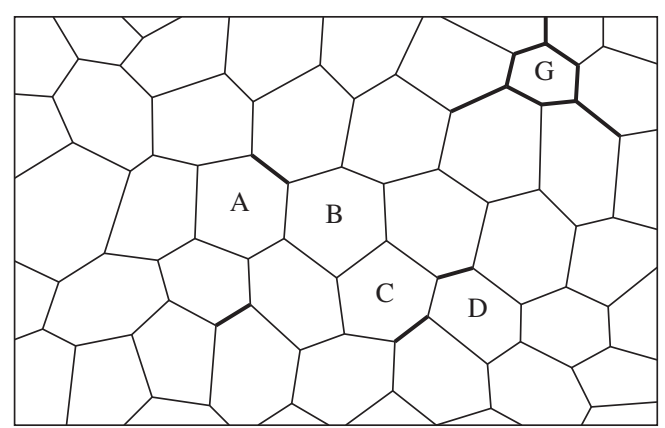

(a)

Subgrain structure before nucleation

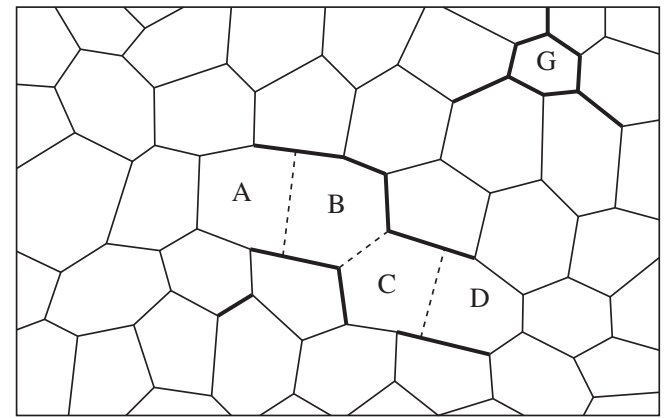

(c)

Further coalescence of subgrains B and C

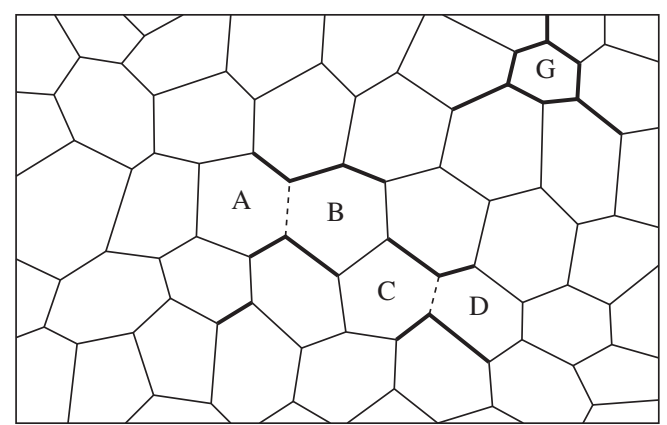

(b)

Coalescence of subgrains A and B, and C and D

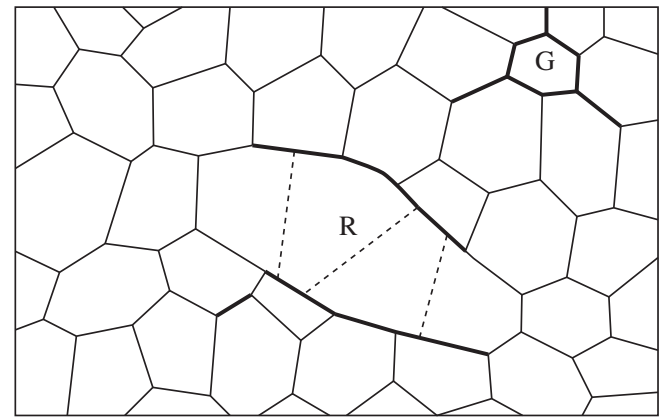

(d)

Formation of a nucleus with high angle boundaries

Figure 5. Schematic representation of a recrystallized grain. The orientation difference of subgrains is represented by the line thickness: a) original structure; b) coalescence of pairs by elimination of common boundaries; c) coalescence of the A/B and C/D pairs; and d) recrystallized grain originating from a group of coalesced subgrains. The thicker lines indicate large angle boundaries ${ }^{36}$. 
variation in lattice orientation (local lattice curvature). In a niobium bicrystal deformed by cold rolling to moderate strains, just to give a single example, highly misoriented boundaries were developed in the microstructure due to deformation banding, many reaching about $55^{\circ}{ }^{70}$. The number of defects is larger when compared with other regions of the plastically deformed metal, creating preferential sites for the occurrence of recrystallization nucleation. These regions contain "potential nuclei" or "embryos", formed during plastic deformation. In metals where twinning, transition banding, and shear banding occur, nucleation will start initially near or at the intersections (in the case of twins) of these heterogeneities. The areas next to pre-exiting grain boundaries, prior to deformation, are also preferential sites. Microscopic observation of samples partially recrystallized (with low volume fraction) reveals that the homogeneous distributions (or even nearly homogeneous) of recrystallization nuclei are very rare. Figure 6 shows an example of the recrystallization nucleation within shear bands in coarse-grained tantalum ${ }^{71}$. Note the predominance of potential nuclei (subgrains) within shear bands in comparison with the surrounding coarser subgrain structure.

\section{Occurrence of the Three Nucleation Mechanisms}

Considering the mechanism of migration of pre-existing grain boundaries, the basic requirement for it to occur is the existence of large strain differences between adjacent grains. Studies conducted by Beck and Sperry ${ }^{31}$ and Bailey ${ }^{37,56,57}$ showed that the mechanism at hand is important for deformations up to $40 \%$ reduction.

The largest dispute in the literature is associated with the occurrence of subgrain coalescence and migration of sub-boundaries. Ex-

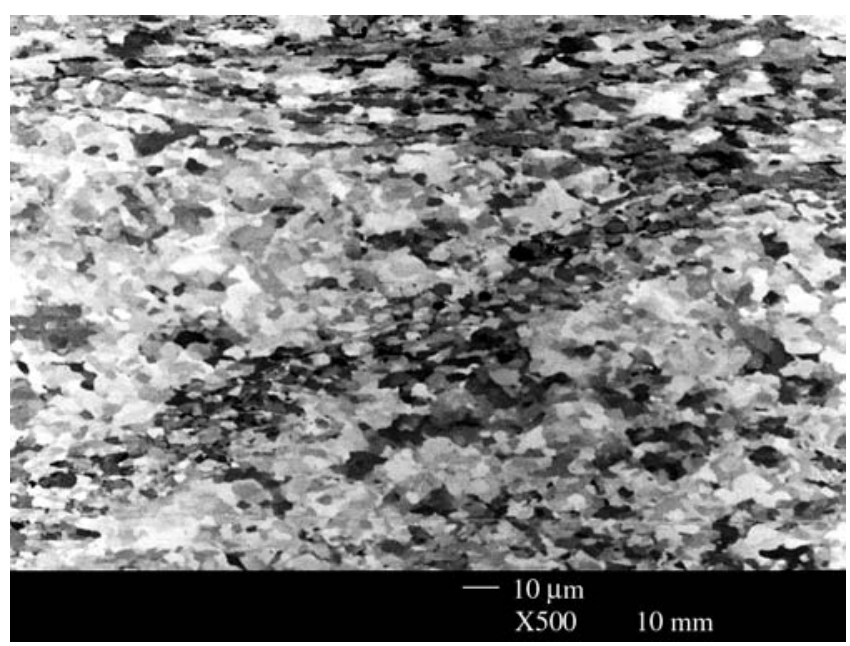

Figure 6. Heterogeneity in the distribution of recrystallized regions due to shear bands. SEM micrograph showing a sample of tantalum deformed by cold swaging to $72 \%$ area reduction and annealed at $900{ }^{\circ} \mathrm{C}$ for 30 minutes $(\mathrm{BSE})^{71}$. perimental data in the literature allows some preliminary prospective considerations to be made on the occurrence of the two last mentioned models. The subgrain migration mechanism seems to be associated with high strains ${ }^{72}$, large spread in the subgrain size distribution ${ }^{73}$, relatively high annealing temperatures ${ }^{61,62}$ and occurs preferentially in low-SFE metals ${ }^{74}$. The mechanism of subgrain coalescence, in turn, seems to be associated with transitions bands ${ }^{73}$, large spread in the distribution of subgrain angles ${ }^{73,75}$, moderate strains ${ }^{73}$, regions next to grain boundaries ${ }^{44,69,72}$, relatively low annealing temperatures ${ }^{61,62,68}$, and metals with high $\mathrm{SFE}^{74}$. On the other hand, the evidences of the subgrain coalescence mechanism obtained from in situ observations on thin samples in TEM have cast some doubt if this mechanism is still applicable to thicker samples. Table 1 summarizes in a tentative way some conditions for which the different recrystallization mechanisms occur, as found in the literature.

During hot deformation, work hardening and restoration mechanisms occur simultaneously. Due to the high temperature, recovery processes take place at high rates, which decrease the driving force for recrystallization. In hot deformation, recrystallization is usually classified as "static", which occurs after deformation or "dynamic", which occurs during deformation. The occurrence of static or dynamic processes will depend on the applied strain (higher strains will favor dynamic processes), strain rates (lower strain rates will favor dynamic processes), stacking fault energy (higher energy will favor static processes) and the temperature. Among the nucleation mechanisms listed above, SIBM and its variations are most likely to take place during and after hot deformation.

In $1995, \mathrm{Nes}^{76}$ published a fairly extensive review on recovery, with a detailed mathematical treatment of the processes involved, including both mechanisms on recrystallization nucleation that take into account subgrain growth. The recent development of 3-D metallography ${ }^{51}$ allows the direct observation of the microstructure evolution in thick strained samples and may put an end to this dispute.

More recently, Ferry and Humphreys ${ }^{77}$ have described the occurrence of discontinuous subgrain growth in deformed and annealed $\{110\}<001>$-oriented aluminum single crystals. After deformation the microstructure showed neither large orientation gradients nor heterogeneities, making the material resistant to recrystallization. Upon annealing, a small number of subgrains grew rapidly and discontinuously to diameters of over $100 \mu \mathrm{m}$. The authors attributed the discontinuous subgrain growth to orientation differences between the subgrains formed during deformation. Later, Monte Carlo simulations showed that abnormal subgrain growth is also a plausible mechanism for recrystallization ${ }^{78}$.

\section{Growth of the Recrystallized Regions}

Migration of high angle boundaries is the fundamental mechanism acting during recrystallization and grain growth, the main difference between them being the driving force related to both phenomena. The driving force for grain growth, being it continuous (normal grain growth) or discontinuous (abnormal grain growth), is the energy of the high angle boundaries. The main driving force for recrystal-

Table 1. Tentative summary for the mechanisms describing the start of recrystallization.

\begin{tabular}{lll}
\hline Strain induced grain boundary migration & \multicolumn{1}{c}{ Sub-boundary migration } & \multicolumn{1}{c}{ Subgrain coalescence } \\
\hline - small strains (up to $\sim 40 \%)$ & $\bullet$ high strains & $\bullet$ moderate strains \\
- hot working & $\bullet$ high temperatures & $\bullet$ relatively low temperatures \\
& $\bullet$ heterogeneous subgrain size distribution & $\bullet$ large spread in the distribution of subgrain \\
& & misorientations \\
& & $\bullet$ transition bands \\
& & $\bullet$ high-SFE metals and alloys \\
\hline
\end{tabular}


lization to occur is the stored energy during straining in the form of crystalline defects. In a region exempt of defects, surrounded by high angle boundaries, recrystallization proceeds by growth of this "nucleus" over the yet non-recrystallized matrix. Another important difference between recrystallization and grain growth is the curvature signal of the migrating high angle boundary. Figure 7 illustrates two examples of reaction fronts (high angle boundaries) advancing into the strained, or better, non-recrystallized matrix. In Figure 7a, the non-recrystallized region is a FCC solid solution of low stacking fault energy (SFE) that suffered little modification during annealing, whereas in Figure $7 b$, the non-recrystallized region of a pure BCC metal with a high SFE presented marked recovery.

Under isothermal conditions, primary recrystallization generally presents an incubation time, associated with the formation of a nucleus. The absence of the incubation time, generally is related to nucleation of the type of pre-existing boundary migration, not having in this case, the need of time for the formation of a high mobility boundary. Growth of the recrystallized regions due to high angle boundaries continues until mutual impingement of recrystallized grains. Primary recrystallization finishes when both reaction fronts meet. The distribution of the recrystallized regions is heterogeneous and grain impingement already occurs even for low volumetric recrystallized fractions.

The migration of high angle boundaries sweeping the microstructure and removing the crystalline defects is an irreversible process. When high angle boundaries move from left to the right, atom flux through the boundary from right to the left is higher than the flux in the opposite direction. Taking into consideration the model in which the atoms overcome individual and independently the activation barrier, by passing from the strained grains to the recrystallized grains, one gets for $\Delta \mathrm{P}<<\mathrm{kT}$ :

$$
\mathrm{V}=(\mathrm{A} \cdot \mathrm{L} \cdot \mathrm{f} / \mathrm{kT}) \cdot \exp (-\Delta \mathrm{A} / \mathrm{kT}) \Delta \mathrm{P}
$$

where $\mathrm{V}$ is the velocity of the interface (high angle boundaries, in the present case), $\Delta \mathrm{P}$ is the driving force for the transformation, $\Delta \mathrm{A}$ is the activation energy, $\mathrm{A}$ is an accommodation factor, $\mathrm{L}$ is the interface thickness, $\mathrm{f}$ is a characteristic frequency, $\mathrm{T}$ is the absolute temperature, and $\mathrm{k}$ is the Boltzmann constant.
Equation 2 shows that migration velocity of grain boundaries is proportional to the driving force for recrystallization and strongly depends on temperature. Migration velocity, V, is frequently presented in a simplified form as a function of two factors: boundary mobility, $\mathrm{M}$, and transformation driving force, $\Delta \mathrm{P}$, and is given by the equation:

$$
\mathrm{V}=\mathrm{M} . \Delta \mathrm{P}
$$

It is important to mention that in the literature there are other formulations for the pre-exponential factor of Equation 2. In reality, the $\Delta \mathbf{P}$ term is the summation of the driving forces and retarding forces acting on the boundary and will be discussed in grater detail in the following. Prior to that, however, boundary mobility will be discussed.

\section{Boundary Mobility}

We shall start this item with a phrase taken from the most recent review article ${ }^{79}$ on boundary mobility:

"Understanding the mobility of grain boundaries is a classic example of a problem in material science that is simple at the level of college student education but a significant challenge for those who would like to be able to understand it in detail."

Despite of this review ${ }^{79}$ emphasizing the non-existence of a satisfactory theory related to boundaries, specially to high angle grain boundaries, nevertheless it is possible to evaluate the effect of some variables on the mobility. Equation 3, that describes migration velocity, does not leave explicit the influence of the crystallographic orientation, which has a considerable importance, known for more than 50 years. Figure 8, taken from Liebmam's doctoral thesis presented in the 50's, shows that migration velocity varies considerably with the misorientation angle $\theta$ (difference in orientation between two grains).

Later works showed that amongst a large orientation variation presented by the boundaries, some distinct steps in mobility could be observed. For small differences in orientation of a few degrees (for example, subgrain boundaries), mobility is very small and can increase or decrease with the orientation difference for mixed boundaries or pure tilt boundaries, respectively ${ }^{81}$. Starting from orientation

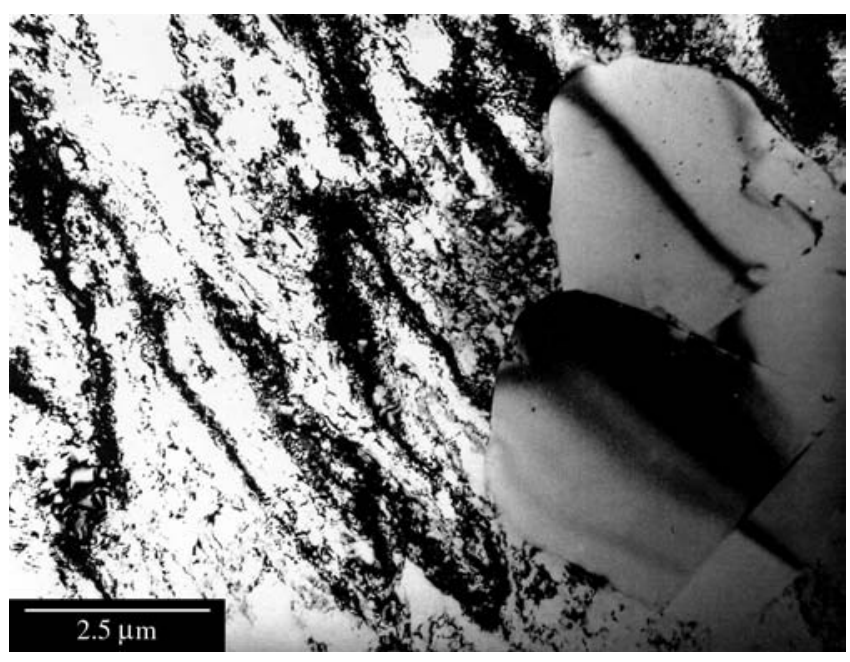

(a)

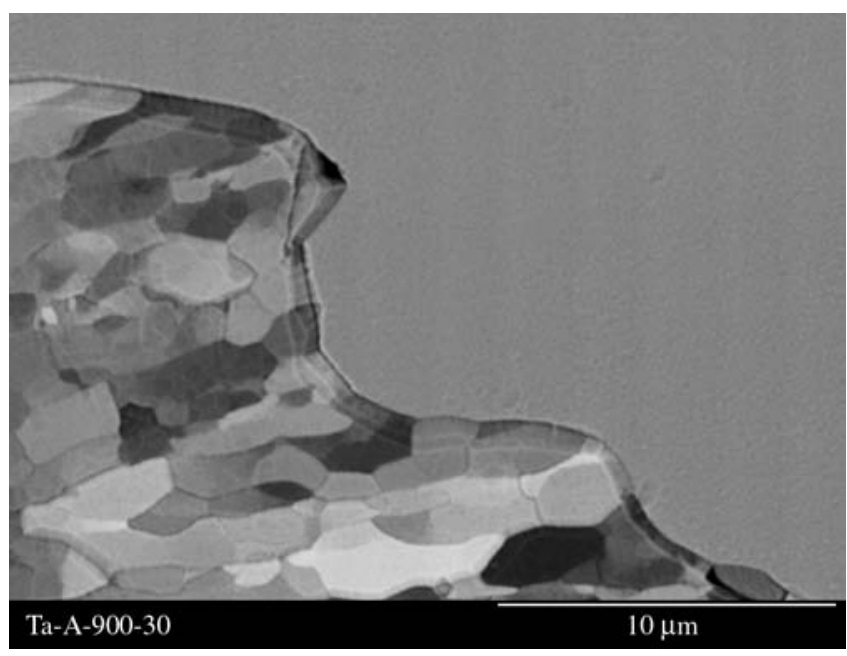

(b)

Figure 7. Reaction fronts (high angle boundaries) migrating during recrystallization: a) transmission electron micrograph of an austenitic stainless steel containing $15 \% \mathrm{Cr}$ and $15 \% \mathrm{Ni}$, cold worked to a $50 \%$ area reduction and annealed at $800{ }^{\circ} \mathrm{C}$ for 3 hours (by kindness of $\mathrm{K}$. Ehrlich, Forschungszentrum Karlsruhe, FZK, Germany); and b) micrograph of a sample of pure tantalum cold worked to $72 \%$ area reduction and annealed at $900{ }^{\circ} \mathrm{C}$ for 30 minutes (SEM, BSE). 
differences of about $1^{\circ}$, mobility increases with $\theta$, as schematically shown in Figure 9. The high angle boundaries, with exception of the twin like boundaries, present a far greater mobility than low angle boundaries.

The activation energy for migration of low angle grain boundaries is very close to that one for volume diffusion (self-diffusion), suggesting that the process is controlled by the mechanism of dislocation climb. On the other hand, activation energy for large angle grain boundary is much smaller, about $3 / 5$ of the activation energy for migration of small angle grain boundaries, indicating that motion of these boundaries is controlled by the atom exchange through the moving boundary ${ }^{82}$. More recent work ${ }^{83,84}$ reviewing the influence of orientation difference on mobility, confirms that high angle boundary mobility $\left(>15^{\circ}\right)$ is about 100 to 1,000 times greater than the low angle

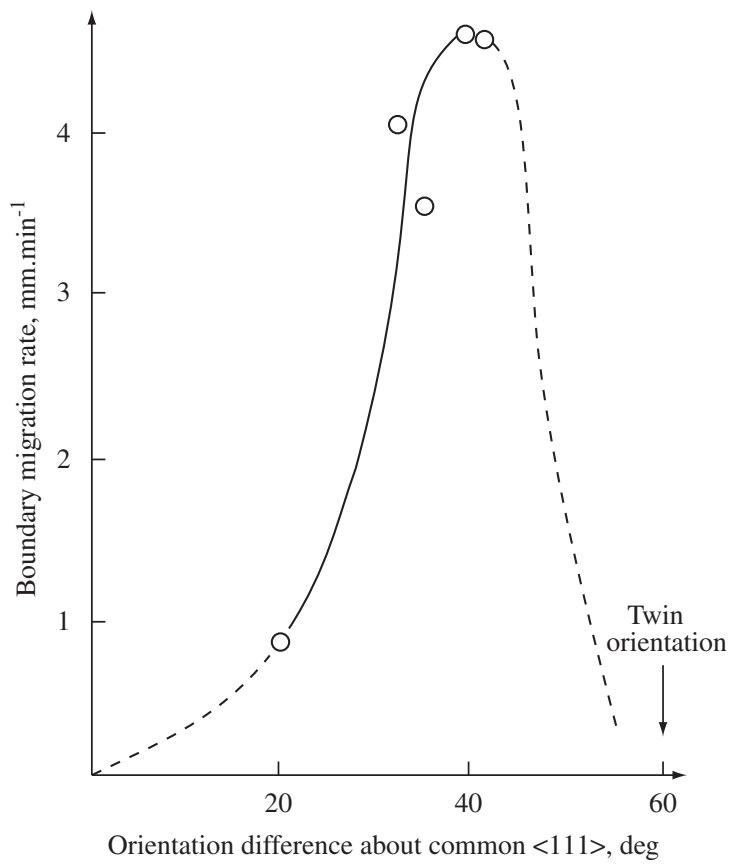

Figure 8. Change in migration rate of the grain boundary $\mathrm{V}$ in aluminum as a function of rotation angle in relation to $<111>$ direction $^{80}$. boundary mobility $\left(2\right.$ to $\left.5^{\circ}\right)$. Activation energies found in high purity copper were 204 and $125 \mathrm{~kJ} / \mathrm{mol}$ for low and high angle boundaries, respectively. These activation energies confirm the hypothesis that low angle boundary mobility is controlled by volume diffusion, while the boundary mobility of high angle boundaries is controlled by diffusion through the boundary. Recent experiments ${ }^{85}$ with tricrystals of aluminum and zinc indicate that the sluggish movement of triple-point grain junctions may control boundary mobility. The geometry and configuration of the junctions play an important role in boundary mobility.

There is extensive evidence that mobilities and activation energies for migration of high angle boundaries are dependent on orientation ${ }^{83}$. There are some characteristic orientations for which boundaries have an especially high mobility. Table 2 shows some examples of materials and their high mobility boundary orientations.

Although many unresolved questions remain about the effects of solutes on anisotropy, the currently available literature shows that significant anisotropy exists with respect misorientation angle, axis and boundary plane ${ }^{79}$. Mobility of special boundaries is associated with the presence of impurities in solid solution (see Figure 10). These boundaries play an important role in secondary recrystallization, i.e.,

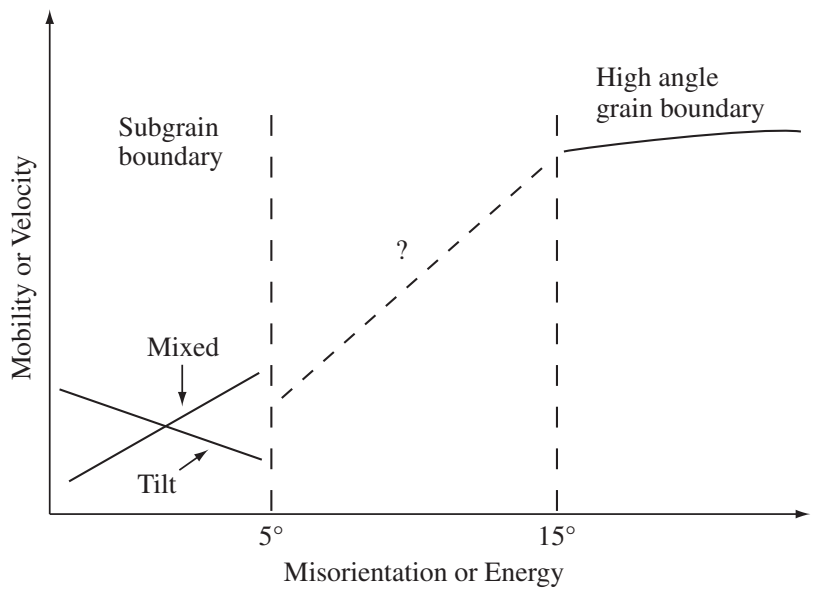

Figure 9. Changes in mobility as a function of the misorientation angle $\theta$ (schematic). Practically there are no data available in the literature for the range of $5^{\circ}<\theta<15^{\circ}$.

Table 2. Crystallographic orientations for the occurrence of high mobility boundaries ${ }^{83}$.

\begin{tabular}{|c|c|c|c|c|c|c|}
\hline \multicolumn{3}{|c|}{ Nearest coincidence relationship } & \multicolumn{2}{|c|}{ Experimental relationship } & \multirow[t]{2}{*}{ Metal } & \multirow[t]{2}{*}{ Structure } \\
\hline Sigma & Rotation & Axis & Rotation & Axis & & \\
\hline \multirow[t]{3}{*}{$\Sigma=7$} & $38.2^{\circ}$ & $<111>$ & $35-45^{\circ}$ & $<111>$ & $\mathrm{Al}$ & fcc \\
\hline & & & $38^{\circ}$ & $<111>$ & $\mathrm{Cu}$ & fcc \\
\hline & & & $36-42^{\circ}$ & $<111>$ & $\mathrm{Pb}$ & fcc \\
\hline \multirow[t]{2}{*}{$\Sigma=13 \mathrm{a}$} & $22.6^{\circ}$ & $<100>$ & $23^{\circ}$ & $<100>$ & $\mathrm{Al}$ & fcc \\
\hline & & & $19^{\circ}$ & $<100>$ & $\mathrm{Cu}$ & fcc \\
\hline \multirow[t]{3}{*}{$\Sigma=13 \mathrm{~b}$} & $27.8^{\circ}$ & $<111>$ & $30^{\circ}$ & $<111>$ & $\mathrm{Cu}$ & fcc \\
\hline & & & $30^{\circ}$ & $<111>$ & $\mathrm{Ag}$ & fcc \\
\hline & & & $20-30^{\circ}$ & $<111>$ & $\mathrm{Nb}$ & bcc \\
\hline \multirow[t]{2}{*}{$\Sigma=13$} & $30^{\circ}$ & $<0001>$ & $30^{\circ}$ & $<0001>$ & $\mathrm{Zn}$ & $\mathrm{cph}$ \\
\hline & & & $30^{\circ}$ & $<0001>$ & $\mathrm{Cd}$ & $\mathrm{cph}$ \\
\hline \multirow[t]{2}{*}{$\Sigma=17$} & $28.1^{\circ}$ & $<100>$ & $26-28^{\circ}$ & $<100>$ & $\mathrm{Pb}$ & fcc \\
\hline & & & $30^{\circ}$ & $<100>$ & $\mathrm{Al}$ & fcc \\
\hline$\Sigma=19$ & $26.5^{\circ}$ & $<110>$ & $27^{\circ}$ & $<110>$ & $\mathrm{Fe}-\mathrm{Si}$ & bcc \\
\hline
\end{tabular}


in situations where the driving force for boundary migration is much smaller $^{86}$. In a simplified and schematic manner, we might affirm (see Figure 10) that special boundaries present higher mobility and are less affected by atoms in solid solution ${ }^{87,88}$. It is interesting to mention that coherent twins present the most coincidence sites $(\Sigma=3)$, yet they have almost zero mobility (see Figure 8).

Finally, it should be pointed out that mobility of mixed boundaries with small orientation differences (up to $5^{\circ}$ ) have been little studied in the literature. Regarding boundaries with intermediate orientations differences (from 5 to $15^{\circ}$ ), no study at all has been conducted. Therefore, it would be desirable that new studies should be conducted in these specific areas ${ }^{89}$.

\section{Driving and Retarding Forces}

As discussed in the previous item, after the nucleus formation, recrystallization is controlled by growth, in which high angle grain boundaries migrate over the strained matrix (non-recrystallized), removing the crystalline defects until grains meet mutually. Elegant experiences with aluminum bicrystals ${ }^{90}$ show in an unequivocal manner the influence of the driving force on the migration velocity of grain boundaries.

Grain boundary migration velocity during primary recrystallization (V) may be given (see Equation 3) by the following equation:

$$
\mathrm{V}=\mathrm{M} . \Sigma \mathrm{F}
$$

where $\Sigma \mathrm{F}=\Delta \mathrm{P}$ is the summation of the forces acting on the reaction front.

The grain boundary mobility has been discussed earlier. In this item we conduct an analysis on the forces that act on a high angle

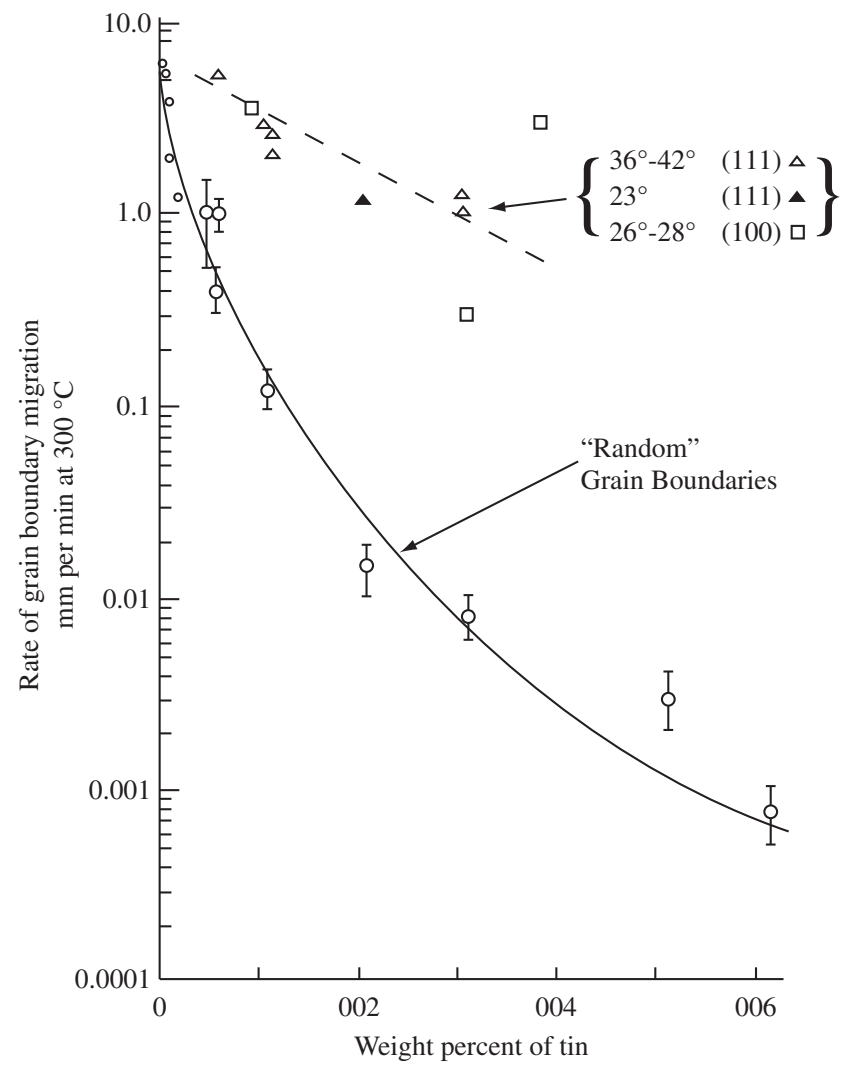

Figure 10. Changes on migration rate of grain boundaries of lead at $300{ }^{\circ} \mathrm{C}$ as a function of tin content, for random grain boundaries and special grain boundaries $^{87,88}$. boundary during its migration. The values of forces presented in the following represent a quantity of energy per unit volume of material, with $\left[\mathrm{J} / \mathrm{m}^{3}\right]$ units. However the $\left[\mathrm{J} / \mathrm{m}^{3}\right]$ unit may be represented by $\left[\mathrm{N} / \mathrm{m}^{2}\right]$ and by mechanical analogy, the acting potentials can be understood as "pressures" applied on high angle boundaries. According to literature ${ }^{53,91-93}$, the main forces acting on the reaction front are: driving force due to straining, driving force due to grain boundaries, driving force due to discontinuous precipitation and retarding forces due to solute atoms and to precipitated particles. In the following we discuss in a separate manner these driving and retarding forces.

\subsection{Driving force due to plastic deformation}

During plastic working of polycrystals some important events occur:

i) Grains change their shape;

ii) Grains rotate and develop preferential orientations (texture);

iii) The quantity (area) of grain boundaries per unit volume increases; and

iv) The quantity of point defects and of dislocations per unit volume increases several orders of magnitude.

Part of the energy spent during the deformation process is stored in the material in the form of crystalline defects. The major contribution is due to dislocations. If the dislocation density prior to deformation is $\rho_{\mathrm{o}}$ and $\rho$ after deformation, the driving force $\mathbf{F}_{\mathrm{N}}$ is given by:

$F_{N}=G \cdot b^{2} \cdot\left(\rho-\rho_{0}\right)$

where $\mathrm{G}$ is the shear modulus and $\mathrm{b}$ is the modulus of the Burgers vector. In practice, the dislocation density after deformation is several orders of magnitude greater than the dislocation density of the material prior to deformation. In this manner, Equation 5 may be simplified to:

$$
F_{N}=G \cdot b^{2} \cdot \rho
$$

For a material (copper, for example) with a dislocation density of $10^{11} \mathrm{~cm} / \mathrm{cm}^{3}$ in the strain hardened condition and of $10^{6} \mathrm{~cm} / \mathrm{cm}^{3}$ after annealing, having G. $\mathrm{b}^{2}=10^{-8} \mathrm{~N}$, we obtain $10^{3} \mathrm{~N} / \mathrm{cm}^{2}$ for $\mathrm{F}_{\mathrm{N}}$. Table 3 compares driving forces (in $\mathrm{J} / \mathrm{mol}$ ) of several phase transformations. It may be observed that recrystallization is one of the solid state reactions with the smallest driving force.

\subsection{Driving force due to the grain boundaries (grain growth)}

The surface energy $(\gamma)$ associated with grain boundaries with average diameter $\mathbf{D}$ is given by the relationship:

$$
\mathrm{F}_{\mathrm{gg}}=(2 \gamma / \mathrm{D})
$$

where $\mathbf{F}_{\mathrm{gg}}$ is the driving force for grain growth. This parameter is associated with the grain growth and secondary recrystallization mechanisms, where the total amount of grain boundaries tends to be minimized. For example, if we consider grain growth in copper (boundary energy of $0.53 \mathrm{~J} / \mathrm{m}^{2}$ ) from $10 \mu \mathrm{m}$ to $250 \mu \mathrm{m}$, we obtain a value of $0.44 \mathrm{~N} / \mathrm{cm}^{2}$ for $\mathrm{F}_{\mathrm{cg}}$.

\subsection{Driving force due to discontinuous precipitation}

Discontinuous precipitation occurs when the high angle boundary migrates over a supersaturated matrix $\left(\alpha_{0}\right)$ and leaves behind it a mixture of phases $(\alpha+\beta)$, frequently with lamellar morphology ${ }^{95}$. It is fairly common that during annealing of strained supersaturated solid solutions recrystallization and discontinuous precipitation occur in a simultaneous and cooperative manner. The difference between the free energy due to supersaturation, $\Delta \mathbf{G}_{\mathrm{C}}$, and the surface energy related to the interfaces of the precipitates, $\Delta \mathbf{G}_{\mathrm{O}}$, give the equation: 
Table 3. Driving forces for some phase transformations and solid state reactions ${ }^{94}$.

\begin{tabular}{lc}
\hline \multicolumn{1}{c}{ Phase transformation } & Driving force $(\mathrm{J} / \mathrm{mol})$ \\
\hline Solidification of copper near to $0 \mathrm{~K}$ & $-13,000$ \\
Solid state precipitation at $1000 \mathrm{~K}$ & $-2,100$ \\
Homogenizing at $1000 \mathrm{~K}$ of $\mathrm{Cu}-40 \% \mathrm{Ni}$ & $-1,900$ \\
Polymorphic transformation of tin $(291 \mathrm{~K})$ & $-2,200$ \\
Polymorphic transformation of iron $(1183 \mathrm{~K})$ & -900 \\
Recrystallization of work hardened copper & -10.5 to - 50.6 \\
Coalescence of fine particles & -20 \\
Grain boundary energy of material with average grain diameter of $30 \mu \mathrm{m}$ and average grain & -0.5 \\
boundary energy of $0.5 \mathrm{~J} / \mathrm{m}^{2}$ & \\
\hline
\end{tabular}

$\mathrm{F}_{\mathrm{gg}}=\left(\Delta \mathrm{G}_{\mathrm{c}} / \mathrm{v}\right)-\left(\Delta \mathrm{G}_{\mathrm{o}} / \mathrm{v}\right)$

Being that:

$\left(\Delta \mathrm{G}_{\mathrm{c}} / \mathrm{v}\right) \sim(2 \mathrm{f} \sigma / \lambda)$

where $\mathrm{v}$ is the molar volume, $\mathrm{f}$ represents the volume fraction of precipitates, $\lambda$ is the spacing between precipitates, and $\sigma$ is the interfacial energy matrix/precipitate. For small solute concentrations $\mathrm{c}_{\mathrm{o}}$, the $\Delta \mathrm{G}_{\mathrm{C}}$ parameter can be written ${ }^{95}$ as follows:

$$
\Delta \mathrm{G}_{\mathrm{c}}=\mathrm{R} \cdot\left(\mathrm{T}-\mathrm{T}_{1}\right) \cdot \mathrm{c}_{\mathrm{o}} \cdot \ln \mathrm{c}_{\mathrm{o}}
$$

where $\mathrm{T}$ is the annealing temperature, $\mathrm{T}_{1}$ is the temperature at which all solute is fully in solid solution, and $\mathrm{R}$ is the gas constant $(8.314 \mathrm{~J} / \mathrm{mol} . \mathrm{K})$. For example, if we consider that 4.9 at. $\%$ of silver $\left(\mathrm{C}_{0}=0.049\right)$ is fully soluble in copper at $779^{\circ} \mathrm{C}\left(\mathrm{T}_{\mathrm{o}}\right)$ and that this alloy presents discontinuous precipitations at $300{ }^{\circ} \mathrm{C}$, Equation 10 gives $5.39 \times 10^{4} \mathrm{~N} / \mathrm{cm}^{2}$ for $\Delta \mathbf{G}_{\mathrm{C}}$. Despite of this value being only an estimate, we can observe that it is very much greater than the driving force for recrystallization.

\subsection{Retarding forces due to particles}

A dispersion of fine particles can retard boundary motion. The reason for this is that part of the available driving force for boundary motion must be used to bypass the particles ${ }^{96}$. The particle dispersion can be thought to exert a pinning force or opposing pressure on the moving boundaries (see Figure 11).

The amount of free energy dissipated depends on the boundaryparticle interaction mechanism. Ashby, Harper and Lewis ${ }^{98}$ identified two possible mechanisms:

i) The boundary may enter and pass through the particle;

ii) The boundary will bend around the particle enveloping and bypassing it.

The first mechanism was the basis of Zener's early calculations in $1948{ }^{99}$ that resulted in:

$\mathrm{F}_{\mathrm{p}}=\left(3 \gamma \mathrm{V}_{\mathrm{vp}} / 2 \mathrm{r}\right)$

Notice that although $\mathrm{F}_{\mathrm{p}}$ is often called pinning force it actually has units of pressure.

The second mechanism was proposed by Rios ${ }^{100}$ and gives a pinning force twice that of Zener's:

$$
\mathrm{F}_{\mathrm{p}}=\left(3 \gamma \mathrm{V}_{\mathrm{vp}} / \mathrm{r}\right)
$$

Rios also showed ${ }^{100-102}$ that the pinning force could be written in terms of the interface area per unit volume of particles, $\mathrm{S}_{\mathrm{vp}}$ :

$$
\mathrm{F}_{\mathrm{p}}=\gamma \mathrm{S}_{\mathrm{vp}}
$$

Supposing an alloy containing $1 \mathrm{vol} . \%$ precipitates $\left(\mathrm{V}_{\mathrm{vp}}=0.01\right)$ of $5 \mu \mathrm{m}$ radius with a grain boundary energy of $\gamma=0.53 \mathrm{~J} / \mathrm{m}^{2}$, we obtain

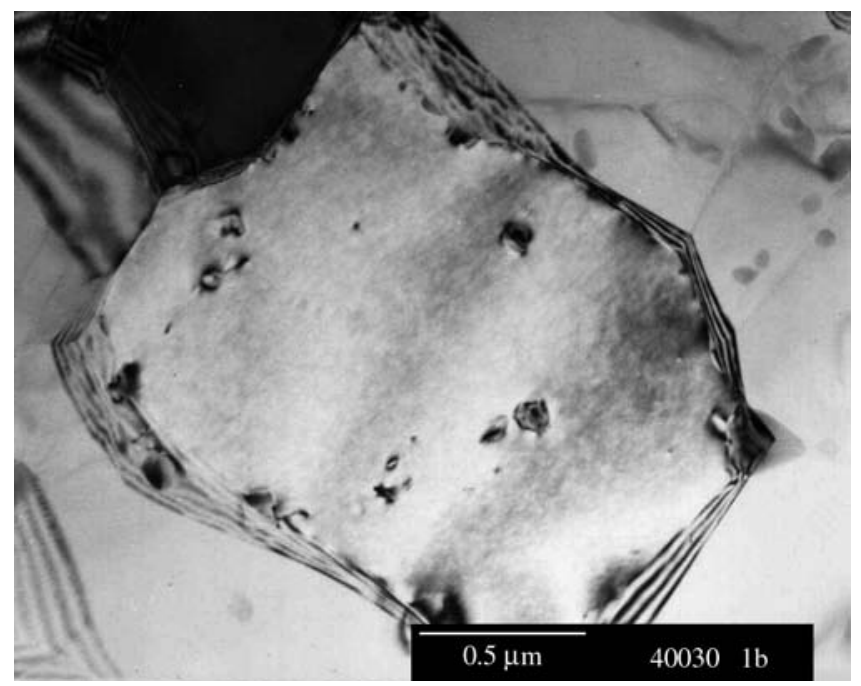

Figure 11. Transmission electron micrograph showing the interaction between intermetallic particles and migrating boundaries during recrystallization of an aluminum alloy ${ }^{97}$.

with the help of Equation 11, the value of $0.16 \mathrm{~N} / \mathrm{cm}^{2}$ for Zener and $0.32 \mathrm{~N} / \mathrm{cm}^{2}$ for Rios. Much of the work concerning particle effects was carried out in the context of grain growth but the pinning force is the same regardless of the nature of the driving force moving the boundary.

\subsection{Retarding force due to solute atoms}

As a first (and coarse) approximation, we may extend the previous model of retarding force due to precipitates $\left(\mathrm{F}_{\mathrm{p}}\right)$ to the retarding force due to solute atoms $\left(\mathrm{F}_{\mathrm{S}}\right)^{93}$. In this case, we use the atom fraction instead of volume fraction and the atomic radius instead of precipitate radii. If we take $1 \%$ of solute having an atomic radius of $0.125 \mathrm{~nm}$ $(1.25 \AA)$ in copper $\left(\gamma=0.53 \mathrm{~J} / \mathrm{m}^{2}\right)$, we obtain $\mathrm{F}_{\mathrm{P}}=6.36 \times 10^{3} \mathrm{~N} / \mathrm{cm}^{2}$. The extension of $\mathrm{F}_{\mathrm{P}}$ (precipitates) to $\mathrm{F}_{\mathrm{S}}$ (atoms) is strictly incorrect; for instance, particles do not move in the lattice, solute atoms can move by diffusion. This leads to two main consequences:

i) There exists an interaction energy $\left(U_{B}\right)$ between the boundary and the solute atom, which is very difficult to be measured or calculated. The solute concentration in the boundaries $(\mathrm{C})$ increases relative to the average concentration $\left(\mathrm{C}_{\mathrm{o}}\right): \mathrm{C}=\mathrm{C}_{\mathrm{o}} \cdot \exp \left(\mathrm{U}_{\mathrm{B}} / \mathrm{RT}\right){ }^{93}$. This explains the large effect of small quantities of solutes on the recrystallization; and

ii) Solute atoms tend to follow the moving grain boundaries by diffusion. In the case of very slow boundaries, these follow the boundary and exert little retarding force (this explains why 
solute atoms have little effect on grain growth and a stronger effect on primary recrystallization). In the case of quick moving boundaries (very large driving forces) the boundary may break away from its impurities and move through the lattice almost unimpeded. The maximum retarding effect occurs for an intermediate range of grain boundary velocities ${ }^{38,93}$.

\subsection{Summation of forces acting during boundary migration}

Starting from grain growth, the acting forces are $F_{c g}, F_{S}$ e $F_{D}$, and the necessary condition for grain growth to occur is:

$$
\mathrm{F}_{\mathrm{gg}}>\mathrm{F}_{\mathrm{s}}+\mathrm{F}_{\mathrm{p}}
$$

On recrystallization, the forces acting at the reaction front are shown in Figure 12. The necessary condition for recrystallization to occur is that the summation of the driving forces is greater than the summation of the retarding forces, i.e.:

$$
\mathrm{F}_{\mathrm{N}}+\mathrm{F}_{\mathrm{C}}>\mathrm{F}_{\mathrm{S}}+\mathrm{F}_{\mathrm{D}}
$$

\section{Experimental Evaluation of the Growth Velocity}

Several microstructural analysis methods have been used to evaluate the growth velocity during recrystallization ${ }^{104}$. Nowadays, the most accepted one is the method proposed by Cahn and Hagel ${ }^{105}$, who demonstrated that the average migration velocity $\left(\mathrm{V}_{\mathrm{CH}}\right)$ of the migrating reaction fronts, i.e., of the large angle grain boundaries between the recrystallized and non-recrystallized areas, can be obtained from quantitative stereological determinations performed on the polished metallographic plane, with the help of equation:

$$
\mathrm{V}_{\mathrm{CH}}=\left(1 / \mathrm{S}_{\mathrm{vr}}\right) \cdot\left(\mathrm{dV}_{\mathrm{vr}} / \mathrm{dt}\right)
$$

where $S_{v r}$ is the interfacial area per unit volume between recrystallized and non-recrystallized regions, $\mathrm{V}_{\mathrm{vr}}$ is the recrystallized volume fraction, and $t$ is the annealing time.

The analysis that has been performed to this point did not take into account two important characteristics of the recrystallization phenomena on the growth rate of the recrystallized regions. The first one is that the distribution of crystalline defects after plastic deformation is very heterogeneous, i.e., the stored energy of the crystalline defects, which is the main driving force for recrystallization, may vary considerably with position within the same grain and from one grain to another.

The second characteristic is that the driving force decreases with time during recrystallization, due to concurrent recovery in the non-recrystallized regions. This competition between recovery and recrystallization is more pronounced in metals and alloys with a BCC crystal structure and in the metals with a FCC crystal structure with high SFE. In these materials, the softening fraction due to recovery and recrystallization is substantially higher than the recrystallized volume fraction ${ }^{106}$.

Both the strain heterogeneity and the occurrence of recovery may lead to a decrease in the speed of grain boundary migration during recrystallization (see Figure 13) and even to the recrystallization stagnation, both leading to deviations ${ }^{107-110}$ in the KJMA equation.

DeHoff ${ }^{111}$ gave an important idea to the analysis of recrystallization kinetics: the concept of the microstructural path. He proposed that the recrystallization follows a path in the $\mathrm{S}_{\mathrm{v}}$ vs. $\mathrm{V}_{\mathrm{v}}$ space. $\mathrm{He}$

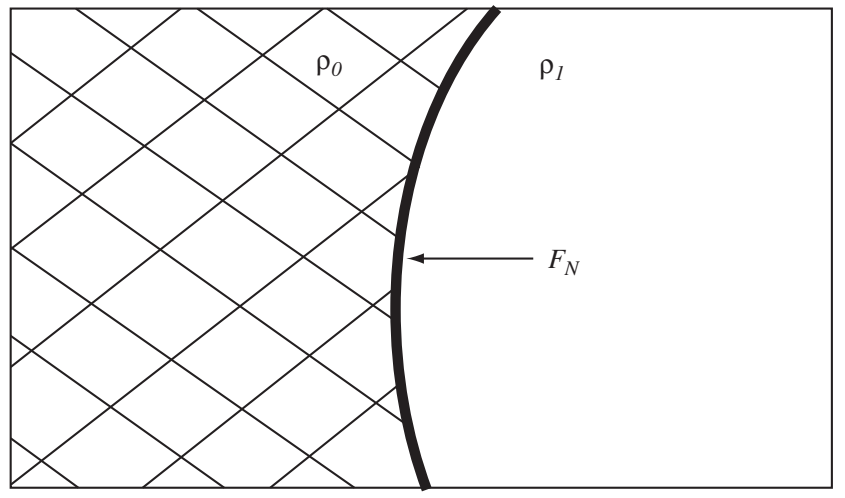

(a)

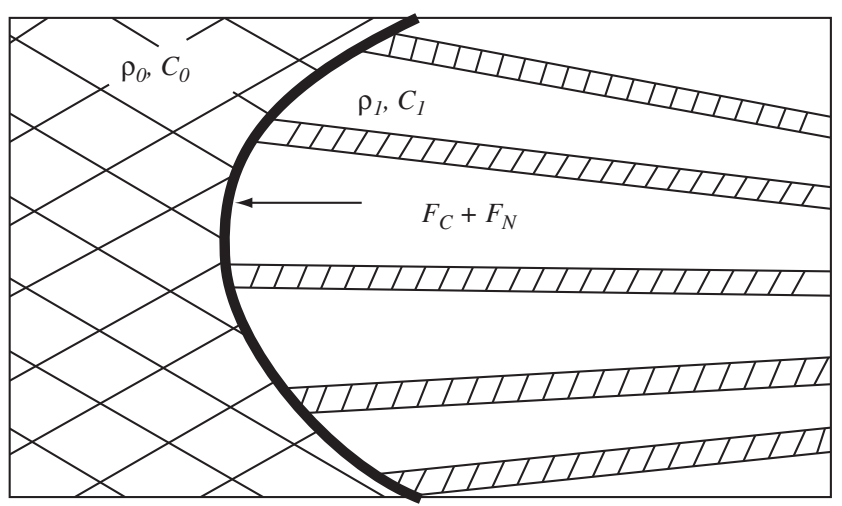

(c)

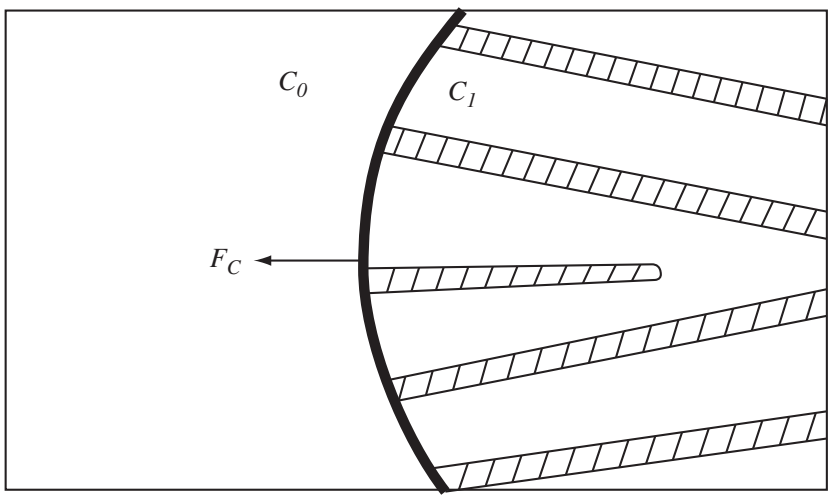

(b)

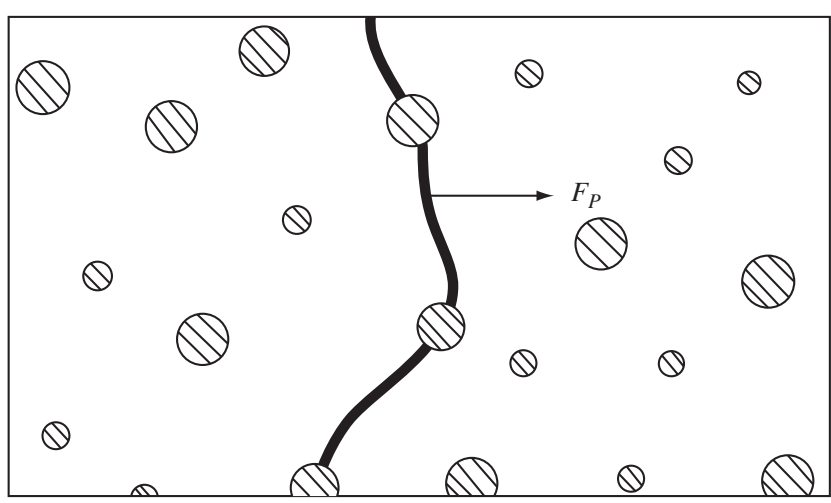

(d)

Figure 12. Forces acting at the reaction front. a) Recrystallization: grain boundary is the reaction front, reducing dislocation density from $\rho_{\mathrm{o}}$ to $\rho_{1}$; b) Discontinuous precipitation: grain boundary is the reaction front, reducing supersaturation from $\mathrm{C}_{0}$ to $\mathrm{C}_{1} ; \mathrm{c}$ ) Discontinuous precipitation combined with recrystallization. Dislocation density $\rho_{0}$ and supersaturation $\mathrm{C}_{\mathrm{o}}$ reduced to $\rho_{1}$ and $\mathrm{C}_{1}$; and d) Dispersed particles exerting retarding force on grain boundary migration ${ }^{53,103}$. 


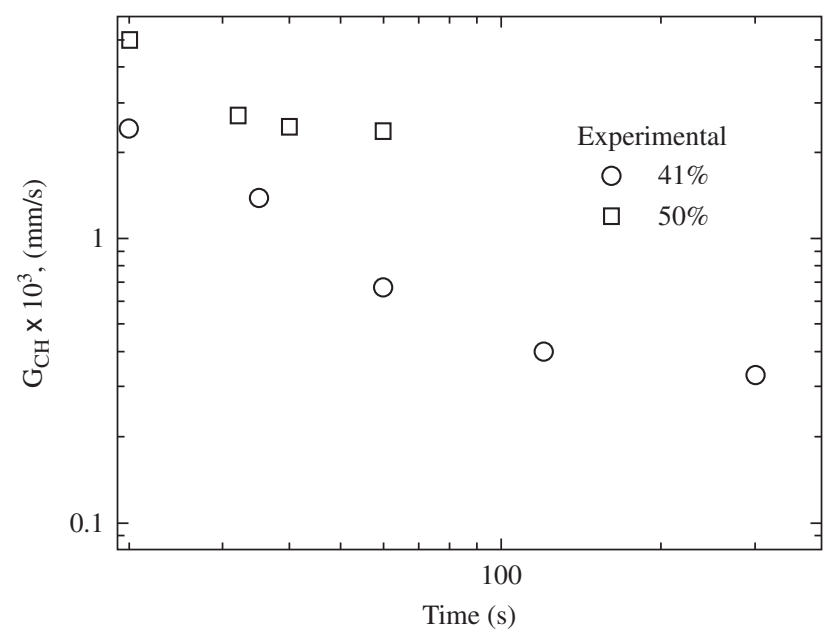

Figure 13. Variation of the average migration rate $\left(\mathrm{V}_{\mathrm{CH}}\right)$ with annealing time at $400{ }^{\circ} \mathrm{C}$ for two levels of cold working (41 and 50\%) in the AA3003 aluminum alloy ${ }^{113,114}$.

demonstrated the usefulness of measuring $\mathrm{S}_{v}$ as a function of time in addition to $\mathrm{V}_{\mathrm{v}}$. The microstructural path method has been subsequently developed and extensively employed, notably by Vandermeer and co-workers ${ }^{104,112}$.

As a final comment, it should be mentioned that the current development of 3-D metallography ${ }^{51}$ is making possible detailed in situ studies (and in relatively thick samples) of the growth in individually recrystallized regions.

\section{Final Remarks}

Some 120 years passed after Kalisher used for the first time in 1881 the technical term or keyword recrystallization, and we may say that a large volume of scientific and technological knowledge has been accumulated. Although various scientific aspects still need further clarification, the available knowledge already allows us a satisfactory control over the microstructure of metallic materials during its thermomechanical processing.

\section{Acknowledgments}

The authors are grateful to FAPESP (São Paulo, Brazil) and CNPq (Brasília, Brazil) for supporting this work.

\section{References}

1. Kalisher S. Ueber den Einfluss der Wärme auf die Molekularstruktur des Zinks. Berichte d. Deut. chem. Gesellschaft. 1881; XIV:2727-2753.

2. Sorby HC. The application of very high powers to the study of the microscopical structure of steel. Journal of the Iron and Steel Institute. 1886; 30(1):140-145.

3. Sorby HC. On the microscopical structure of iron and steel. Journal of the Iron and Steel Institute. 1887; 31(1):255-288.

4. Stead JE. The crystalline structure of iron and steel. Journal of the Iron and Steel Institute. 1898; 53(1):145-205.

5. Ewing JA, Rosenhain W. The crystalline structure of metals. Proceedings of the Royal Society. 1899; 65:85-90.

6. Ewing JA, Rosenhain W. The crystalline structure of metals. Philosophical Transactions of the Royal Society A. 1900; 193:353-372.

7. Ewing JA, Rosenhain W. The crystalline structure of metals. Philosophical Transactions of the Royal Society A. 1900; 195:279-301.

8. Laue MV. Röntgenstrahlinterferenzen. Zeitschrift für Physik. 1913; 14:1075-1079.
9. Miller WH, Deighton J J. A treatise on crystallography. Cambridge; 1839.

10. Rosenhain W. An introduction to physical metallurgy. London: Constable; 1914.

11. Carpenter $\mathrm{HCH}$, Elam CF. Crystal growth and recrystallization in metals. Journal of the Institute of Metals. 1920; 24:83-131.

12. Czochralski J. Geschichtlicher Beitrag zur Frage der Rekristallisation. Zeitschrift für Metallkunde. 1927; 19:316-320.

13. Jeffries Z, Archer RS. Grain growth and recrystallization (Cap.5). In: The science of metals. London: McGraw-Hill Book Company, Inc; 1924. p. 86-114.

14. Alterthum H. Zur Theorie der Rekristallisation. Zeitschrift für Metallkunde. 1922; 14:417-424.

15. Wever F. Über die Walzstruktur kubisch kristallisierender Metalle. Zeitschrift für Physik. 1924; 28:69-90.

16. Burgers WG, Louwerse PC. Über den Zusammenhang zwischen Deformationsvorgang und Rekristallisationstextur bei Aluminium. Zeitschrift für Physik. 1931; 67:605-678.

17. Beck PA, Sperry PR, Hu H. The orientation dependence of the rate of boundary migration. Journal of Applied Physics. 1950; 21:420-425.

18. Orowan E. Zur Kristallplastizität: iii. Über den Mechanismus des Gleitvorganges. Zeitschrift für Physik. 1934; 89:634-659.

19. Taylor GI. The mechanism of plastic deformation of crystals. Part I-Theoretical. Proceedings of the Royal Society of London. 1934; 145(A):312-387.

20. Polanyi M. Über eine Art Gitterstörung die einen Kristall plastich machen könnte. Zeitschrift für Physik. 1934; 89:660-664.

21. Kolmogorov AN. Sobre a teoria estatística da cristalização de metais. Izv. Akademii Nauk SSSR - Ser. Matemat. 1937; 1:355-359. (Portuguese translation kindly provided by Prof. Dr. J. A. Cintra, FGV, S. Paulo, Brazil)

22. Johnson WA, Mehl RF. Reaction kinetics in processes of nucleation and growth. Transactions of the Metallurgical Society of AIME. 1939; 135:416-441.

23. Avrami M. Kinetics of phase change I. Journal of Chemical Physics. 1939; 7(12):1103-1112.

24. Avrami M. Kinetics of phase change II. Journal of Chemical Physics. 1940; 8(2):212-224

25. Avrami M. Kinetics of phase change III. Journal of Chemical Physics. 1941; 9(2):177-184.

26. Burgers WG. Rekristallisation, verformter Zustand und Erholung. Akademischer Verlagsgesellschaft: Leipzig; 1941.

27. Cahn RW. Recrystallization of single crystals after plastic bending. Journal of the Institute of Metals. 1949; 76(2):121-143.

28. Heidenreich RD. Electron microscope and diffraction study of metal crystal textures by means of thin sections. Journal of Applied Physics. 1949; 20(10):993-1010.

29. Beck PA. The formation of recrystallization nuclei. Journal of Applied Physics. 1949; 20(6):633-634.

30. Cahn RW. A new theory of recrystallization nuclei. Proceedings of the Physical Society. ser.AI. 1950; 63(364):323-336.

31. Beck PA, Sperry PR. Strain induced boundary migration in high purity aluminum. Journal of Applied Physics. 1950; 21(2):150-152.

32. Burke JE, Turnbull D. Recrystallization and grain growth. Progress in Metal Physics. 1952; 3:220-292. London: Pergamon Press.

33. Swan PR. In: Thomas G, Washburn J, editors. Dislocations arrangements in face centered cubic metals. Electron Microscopy and Strength of Crystals. New York: Interscience; 1963. p.131-181.

34. Keh AS, Weissman S. In: Thomas G, Washburn J, editors. Deformation structure in body-centered cubic metals. Electron Microscopy and Strength of Crystals. New York: Interscience; 1963. p.231-300.

35. Hu H. Direct observations on the annealing of Si-Fe crystals in the electron microscope. Transactions of the Metallurgical Society of AIME. 1962; 224(1):75-84. 
36. Hu H. In: Thomas G, Washburn J, editors. Recrystallization by subgrain coalescence. Electron Microscopy and Strength of Crystals. New York: Interscience; 1963. p. 564-573.

37. Bailey JE, Hirsch PB. The recrystallization process in some policrystalline metals. Proceedings of the Royal Society of London. 1962; 267(1328):11-30.

38. Lücke K, Detert K. A quantitative theory of grain boundary motion and recrystallization in metals in the presence of impurities. Acta Metallurgica. 1957; 5(11):628-637.

39. Doherty RD, Martin JW. The effect of a dispersed second phase on the recrystallization of aluminium-copper alloys. Journal of the Institute of Metals. 1962-3; 91:332-338.

40. Ferran GL, Doherty RD, Cahn RW. Kossel line determination of orientation of new grains formed by recrystallization of aluminium. Acta Metallurgica. 1971; 19(10):1019-1029.

41. Doherty RD, Cahn RW. Nucleation of new grains in recrystallization of cold worked metals. Journal of Less Common Metals. 1972; 28(2):279-296.

42. Bellier SP, Doherty RD. Structure of deformed aluminum and its recrystallization - investigations with transmission Kossel diffraction. Acta Metallurgica. 1977; 25(5):521-538.

43. Inokuti Y, Doherty RD. Transmission Kossel study of structure of compressed iron and its recrystallization behavior. Acta Metallurgica. 1978; 26(1):61-80.

44. Faivre P, Doherty RD. Nucleation of recrystallization in compressed aluminium - studies by electron microscopy and Kikuchi diffraction. Journal of Materials Science. 1979; 14(4): 897-919.

45. Rollet AD, Srolovitz DJ, Doherty RD, Anderson MP. Computer simulation of recrystallization in non-uniformly deformed metals. Acta Metallurgica. 1989; 37(2):627-639.

46. Haessner F, editor. Recrystallization of metallic materials. Stuttgart: Dr. Riederer-Verlag GmbH; 1978.

47. Randle V. Microtexture determination and its applications. London: The Institute of Materials; 1992.

48. Humphreys FJ, Ferry M. Applications of electron backscattered diffraction to studies of annealing of deformed metals. Materials Science and Technology. 1997; 13(1):85-90.

49. Randle V. Application of electron backscatter diffraction to grain boundary characterisation. International Materials Reviews. 2004; 49(1):1-11.

50. Czubayko U, Molodov D, Petersen BC, Gottstein G, Shvindlerman LS. An $\mathrm{X}$-ray device for continuous tracking of moving interfaces in crystalline solids. Measurements Science and Technology. 1995; 6(7):947-952.

51. Schmidt S, Nielsen SF, Gundlach C, Margulies L, Huang X, Juul Jensen D. Watching the growth of bulk grains during recrystallization of deformed metals. Science. 2004; 305(5681):229-232.

52. Haessner F, editor. Systematic survey and basic problems of recrystallization. Recrystalization of metallic materials. Stuttgart: Dr. Riederer Verlag; 1978. p. 1-10.

53. Hornbogen E, Köster U. In: Haessner F, editor. Recrystallization of two-phase alloys. Recrystalization of metallic materials. Stuttgart: Dr. Riederer Verlag; 1978. p. 159-194.

54. Humphreys FJ, Chan HM. Discontinuous and continuous annealing phenomena in aluminium-nickel alloy. Materials Science and Technology. 1996; 12(2): 143-148.

55. Doherty RD. [personal communication]. 2003, Jul.17.

56. Bailey JE. Electron microscope observations on the annealing processes occurring in cold worked silver. Philosophical Magazine. 1960; 5(53):485-497.

57. Bailey JE. In: Thomas G, Washburn J, editors. Electron microscope observations on recovery and recrystallization processes in cold worked metals. Electron Microscopy and Strength of Crystals. New York: Interscience; 1963. p. 535-564.

58. Cotterill P, Mould PR. Recrystallization and grain growth in metals. London: Surrey University; 1976. p. 85.
59. Cottrell AH. In: Chalmers B, editor.Theory of dislocations. Progress in metal physics. 1953; 4:251-255. London: Pergamon Press.

60. Sandström R, Lehtinen B, Hedman E, Groza I, Karlsson S. Subgrain growth in $\mathrm{Al}$ and $\mathrm{Al}-1 \% \mathrm{Mn}$ during annealing. Journal of Materials Science. 1978; 13(6):1229-1242.

61. Varma K, Willitis BL. Subgrain growth in aluminum during static annealing. Metallurgical Transactions A. 1984; 15(A):1502-1503.

62. Walter JL, Koch EF. Substructures and recrystallization of deformed (100) [001]-oriented crystals of high purity silicon-iron. Acta Metallurgica. 1963; 11(8):923-938.

63. Blum W, Schlögl C, Meier M. Subgrain formation and subgrain boundary migration in $\mathrm{Al}-5 \mathrm{Mg}$ during high temperature deformation in the range of class - A behaviour in comparison with pure aluminium. Zeitschrift für Metallkunde. 1995; 86(9):631-637.

64. Smith CS. Discussion on paper by Mr.J.S.Bowles and Dr. W. Boas. "The effect of crystal arrangements on 'secondary recrystallization' in metals". Journal of the Institute of Metals. 1947/48; 74:742-758.

65. Li JCM. Possibility of subgrain rotation during recrystallization. Journal of Applied Physics. 1962; 33(10):2958-2965.

66. Doherty RD, Szpunar JA. Kinetics of subgrain coalescence-a reconsideration of the theory. Acta Metallurgica. 1984; 32(10):1789-1798.

67. Jones AR, Ralph B, Hansen N. Subgrain coalescence and the nucleation of recrystallization at grain boundaries in aluminum. Proceedings of the Royal Society of London. 1979; 368(A):345-357.

68. Jones AR, Ralph B, Hansen N. Nucleation of recrystallization in aluminium containing dispersions of alumina. Metal Science. 1979; 13:149-154.

69. Jones AR. Grain boundary phenomena during the nucleation of recrystallization. In: Grain-boundary structure and kinetics. Ohio: ASM, Metals Park; 1980. p. 379-425.

70. Sandim HRZ, Lins JFC, Pinto A L, Padilha A F. Recrystallization behavior of a cold-rolled niobium bicrystal. Materials Science and Engineering A. 2003; 354(1-2):217-228.

71. Sandim HRZ, Padilha AF, Randle V, Blum W. Grain subdivision and recrystallization in oligocrystalline tantalum during cold swaging and subsequent annealing. International Journal of Refractory Metals and Hard Materials. 1999; 17(6):431-435.

72. Ray RK, Hutchinson WB, Duggan BJ. A study of the nucleation of recrystallization using HVEM. Acta Metallurgica. 1975; 23(7):831-840.

73. Kreisler A, Doherty RD. Structure of well defined deformation bands and formation of recrystallization nuclei in aluminium. Metal Science. 1978; 12:551-560.

74. McQueen HJ, Jonas JJ. Recovery and recrystallization during high temperature deformation. In: Treatises on Materials Science and Technology. (Plastic Deformation of Materials). 1975; 6:393-493.

75. Doherty RD. Nucleation. In: Haessner F, editor. Recrystallization in Metallic Materials. Stuttgart: Dr. Riederer Verlag; 1978. p. 23-61.

76. Nes E. Recovery revisited. Acta Metallurgica et Materialia. 1995; 43(6):2189-2207.

77. Ferry M, Humphreys FJ. Discontinuous subgrain growth in deformed and annealed $\{110\}<001>$ aluminium single crystals. Acta Materialia. 1996; 44(4):1293-1308.

78. Holm EA, Miodownik MA, Rollet AD. On abnormal subgrain growth and the origin of recrystallization nuclei. Acta Materialia. 2003; 51(9):2701-2716.

79. Rollet AD, Gottstein G, Shvindlerman L, Molodov D. Grain boundary mobility - a brief review. Zeitschrift für Metallkunde. 2004; 95(4):226-229.

80. Liebman B, Lücke K, Masing G. Untersuchung über die Orientierungsabhängigkeit der Wachstumsgeschwindigkeit bei der primären Rekristallisation von Aluminium-Einkristallen. Zeitschrift für Metallkunde. 1956; 47(2):57-63.

81. Christian JW. In: Raynor GV, editor. The theory of transformations in metals and alloys. International Series of Monographs in Metal Phys- 
ics and Physical Metallurgy. vol.7. London: Pergamon Press; 1965. p. 710-742.

82. Viswanathan R, Bauer CL. Kinetics of grain boundary migration in copper bicrystals with [001] rotation axes. Acta Metallurgica. 1973; 21(8): 1099-1109.

83. Humphreys FJ, Hatherly M. Recrystallization and related annealing phenomena. Oxford: Pergamon Press; 1996. p. 85-126.

84. Doherty RD, Hughes DA, Humphreys FJ, Jonas J, Juul Jensen D, Kassner $\mathrm{ME}$ et al. Current issues in recrystallization: a review. Materials Science and Engineering A. 1997; A238:219-274.

85. Molodov DA. In: Gottstein G, Molodov DA, editors. Grain boundary character - a key factor for grain boundary control. Recrystallization and grain growth. vol.1. Aachen: Springer Verlag; 2001. p.21-38.

86. Kronberg ML, Wilson FH. Secondary recrystallization in copper. Transactions of the Metallurgical Society of AIME. 1949; 185(8):501-514.

87. Aust KT, Rutter JW. Grain boundary migration in high-purity lead and dilute lead-tin alloys. Transactions of the Metallurgical Society of AIME. 1959; 215(1):119-127.

88. Aust KT, Rutter JW. Kinetics of grain boundary migration in high-purity lead containing very small additions of silver and of gold. Transactions of the Metallurgical Society of AIME. 1960; 218(4):682-688.

89. Hu H, Rath BB, Vandermeer RA. In: Chandra T, editor. An historical perspective and overview of the annealing studies of cold worked metals. Recrystallization '90. Warrendale: TMS; 1990. p. 3-16.

90. Rath $\mathrm{BB}, \mathrm{Hu} \mathrm{H}$. Effect of driving force on the migration of high-angle tilt grain boundaries in aluminum bicrystals. Transactions of the Metallurgical Society of AIME. 1969; 245(7):1577-1585.

91. Köster U. Recrystallization involving a second phase. Metal Science. 1974; 8:151-160.

92. Lücke K, Stüwe HP. In: Himmel L, editor. On the theory of grain boundary motion. Recovery and recrystallization of metals. New York: Interscience; 1963. p. 171-210.

93. Stüwe HP. In: Haessner F, editor. Driving and dragging forces in recrystallization. Recrystallization of metallic materials. Stuttgart: Dr. Riederer Verlag; 1978. p. 11-21.

94. Martin JW, Doherty RD. Stability of microstructure in metallic systems. Cambridge: Cambridge University Press; 1976. p. 7-10.

95. Predel B. Heterogene Gleichgewichte. Darmstadt: Steinkopff Verlag; 1982. p. 285.

96. Rios PR, Gottstein G, Shvindlerman LS. An irreversible thermodynamic approach to normal grain growth with a pinning force. Materials Science and Engineering A. 2002; 332(1-2):231-235.

97. Pimenta Jr. FC, Arruda ACF, Padilha AF. Resistance to recrystallization in Al-1\%Mn alloys. Zeitschrift für Metallkunde. 1986; 77(8):522-528.
98. Ashby MF, Harper J, Lewis J. The interaction of crystal boundaries with second-phase particles. Transactions of the Metallurgical Society of AIME. 1969: 245(8):413-420.

99. Zener C, Smith CS. Grains, phases and interfaces: an interpretation of microstructure. Transactions of the Metallurgical Society of AIME. 1948; 175:11-51.

100.Rios PR. A theory for grain-boundary pinning by particles. Acta Metallurgica. 1987; 35(12):2805-2814.

101. Rios PR. On the relationship between pinning force and limiting grain radius. Scripta Materialia. 1996; 34(8):1185-1188.

102.Rios PR, Fonseca GS. Grain boundary pinning by $\mathrm{Al}_{6} \mathrm{Mn}$ precipitates in an Al-1wt\%Mn alloy. Scripta Materialia. 2004; 50(1):71-75.

103.Hornbogen E. Electron microscopical investigation of recrystallization of alloys in which precipitation can occur. Praktische Metallographie. 1970; 7:349-360.

104. Vandermeer RA, Juul Jensen D. The migration of high angle grain boundaries during recrystallization. Interface Science. 1993; 6(1-2):95-104.

105.Cahn JW, Hagel W. In: Zackay Z D, Aaronson H I, editors. Decomposition of austenite by diffusional processes. New York: Interscience Publishers; 1960. p. 131-196.

106. Stüwe HP. Einführung in die Werkstoffkunde. $2^{\text {nd }}$ edition. Mannheim: Wissenschaftsverlag, Auflage; 1991. p. 116-130.

107. Vandermeer RA, Rath BB. Interface migration during recrystallization: the role of recovery and stored energy gradients. Metallurgical Transactions A. 1990; 21(A):1143-1149.

108. Rios PR. Modeling time dependence of the average interface migration rate in site-saturated recrystallization. Metallurgical and Materials Transactions A. 1997; 28(A):939-946.

109. Stüwe HP, Padilha AF, Siciliano Jr F. Competition between recovery and recrystallization. Materials Science and Engineering A. 2002; A233: 361-367.

110.Hupalo MF, Padilha AF, Sandim HRZ, Kliauga AM. Cold swaging, recovery and recrystallization of oligocrystalline Incoloy MA 956 - Part I and II. ISIJ International. 2004; 44:1903-1919.

111.DeHoff RT. In: Hansen N, Juul Jensen D, Leffers T, Ralph B, editors. Microstructural evolution during recrystallization. Proceedings of Annealing Processes - Recovery, Recrystallization and Grain Growth. Denmark: Riso National Laboratory, Roskilde; 1986. p. 35-52.

112. Vandermeer RA, Juul Jensen D. Microstructural path and temperature dependence of recrystallization in commercial aluminum. Acta Materialia. 2001; 49(11):2083-2094.

113. Rios PR, Padilha AF. Microstructural path of recrystallization in a commercial Al-Fe-Mn-Si (AA3003) alloy. Materials Research (Brazil). 2004; 6:605-613.

114.Rios PR, Padilha AF. Comment on "Microstructural path and temperature dependence of recrystallization in commercial aluminum". Scripta Materialia. 2004; 48(11):1561-1564. 